\title{
Dialogic analysis vs. discourse analysis of dialogic pedagogy: Social science research in the era of positivism and post-truth
}

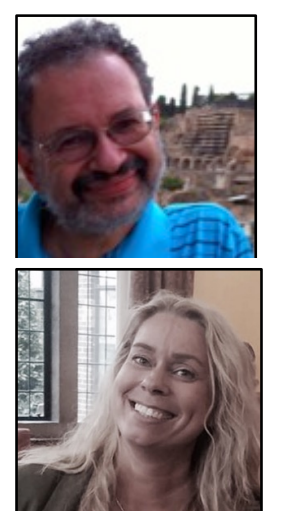

Eugene Matusov

University of Delaware, USA

Tina Kullenberg

Kristianstad University, Sweden

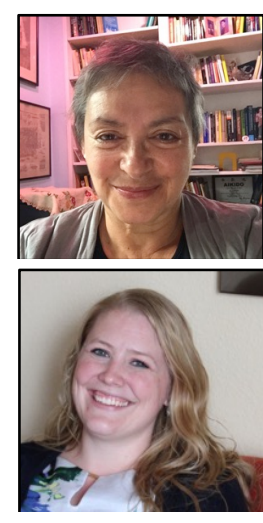

Ana Marjanovic-Shane

Independent Scholar, USA

Kelly Curtis

University of Delaware, USA

\begin{abstract}
The goal of this article is to compare and contrast dialogic analysis versus discourse analysis of dialogic pedagogy to address Bakhtin's quest for "human sciences" and avoid modern traps by positivism and by post-truth. We argue that dialogic analysis belongs to dialogic science, which focuses on studying "the surplus of humanness" (Bakhtin, 1991, $p$. 37). "The surplus of humanness" is "a leftover" from the biologically, socially, culturally, and psychologically given - the typical and general - in the human nature. It is about the human authorship of the ever-unique meaning-making. Dialogic analysis involves the heart and mind of the researchers who try to reveal and deepen the meanings of the studied phenomena by addressing and replying to diverse research participants, other scholars, and anticipated readers (Matusov, Marjanovic-Shane, \& Gradovski, 2019, in press). We argue that dialogic science is concerned with meta-inquiries such as, "What does something in question mean to diverse people, including the researchers, and why? How do diverse people address and reply to diverse meanings?" In contrast, traditional, positivistic, science is concerned with meta-inquiries such as, "How things really are? What is evidence for that? How to eliminate any researchers' subjectivity from the research?" (Matusov, 2019, submitted). Positivist (and monologic) science focuses on revealing patterns of actions, behaviors, and relationships. We argue that in the study of dialogic pedagogy, it is structural and/or functional discourse analysis that focuses on studying the given and objective aspects of dialogic pedagogy. In the paper, we consider, describe, interpret, and dialogically re-analyze a case of dialogic analysis involving science education coming from David Hammer's and Emily van Zee's (2006) book. We also discuss structural and functional discourse analysis of two pedagogical cases, a monologic and a dialogic one, provided by David Skidmore (2000). We dialogically re-analyze these two cases and Skidmore's research. We conclude that in research on dialogic pedagogy (and beyond, on social sciences in general) both dialogic science (involving dialogic analysis) and positivist science (involving discourse analysis) are unavoidable and needed, while providing the overall different foci of the research. We discuss the appropriateness and the limitations of discourse analysis as predominantly searching for structural-functional patterns in the classroom discourses. We discuss dialogic tensions in the reported dialogues that cannot be captured by discourse analysis search for patterns. Finally, we discuss two emerging issues among ourselves: 1) whether discourse analysis is always positivist and 2) how these two analytic approaches complement each other while doing research on dialogic pedagogy (and beyond).
\end{abstract}


Eugene Matusov is a Professor of Education at the University of Delaware. He studied developmental psychology with Soviet researchers working in the Vygotskian paradigm and worked as a schoolteacher before immigrating to the United States. He uses sociocultural and Bakhtinian dialogic approaches to education. His recent books are: Matusov, E. (2017). Nikolai N. Konstantinov's authorial math pedagogy for people with wings, Matusov, E. \& Brobst, J. (2013). Radical experiment in dialogic pedagogy in higher education and its Centauric failure: Chronotopic analysis, and Matusov, E. (2009). Journey into dialogic pedagogy.

Ana Marjanovic-Shane is an Independent scholar in Philadelphia, USA. She studies meaning making in human development, dialogic educational relationships and events, democracy in education, dialogic teacher orientation, the role of imagination, drama, play and critical dialogue in education. In her studies, she is developing a dialogic sociocultural paradigm, inspired by a Bakhtinian dialogic orientation. Her articles were published by "Mind, Culture, Activity Journal", "Learning, Culture and Social Interaction", and as book chapters in books on play, education, and democracy. Her most recent publication is: MarjanovicShane et al, (2019). Idea-dying in critical ontological democratic dialogue in classrooms. Learning, Culture and Social Interaction.

Tina Kullenberg holds a Doctor of Philosophy in Education, currently working at Kristianstad University (Sweden) as a lecturer with teacher students from various programs, and the Master's program in Educational Science. Her research focuses on pedagogical communication, applying dialogic and sociocultural perspectives on teaching and learning. Lately she has been especially engaged in Bakhtininspired approaches to education. She also has a special interest in addressing democratic issues with a relational lens, for example, exploring the intricate dynamics of power-relations in educational dialogues between teachers and students or peers, premises for student agency, and other institutionally embedded dilemmas or opportunities in schooling of different types. Moreover, she has a background from the area of music education, in theory and practice.

Kelly Curtis is currently a PhD student in mathematics education at the University of Delaware with a Bachelor's degree in mathematics and a Master's degree in mathematics education from Brigham Young University. She has taught mathematics and mathematics content courses for pre-service teachers at the secondary and college level for six years (in Utah, Colorado, and now Delaware). She is currently working on her dissertation which has to do with how cognitive demand of mathematical tasks affects the way that teachers and students interact around mathematics. She wants to help teachers learn how to improve their teaching skills. She is especially interested in mathematical discourse and how teachers can implicitly send messages to students about what it means to do mathematics and be good at mathematics.

\section{Acknowledgements}

We are thankful to Mikhail Gradovski, Tara Ratnam, David Hammer, and Emily van Zee for providing their critical feedback on previous drafts of this manuscript.

$\cos 0380$

\section{Introduction}

In our observation, broadly defined "dialogic pedagogy," which emphasizes the importance of dialogue for education, has mainly, but not exclusively, been studied discursively. Since the mid1970s, discourse analysis - i.e., finding structural and/or functional patterns of classroom interactions - has been extremely helpful for problematizing conventional monologic pedagogy. Specifically, the discovery and critique of "the triadic exchange" (Sinclair \& Coulthard, 1975) - when the teacher initiates a discourse by 
asking students a disinterested, quizzing question, a student replies, and then the teacher evaluates and/or provides a follow up guidance - set innovative educators and educational researchers on a task of finding alternative pedagogies, evaluated through discourse analysis.

In our paper, we challenge this predominant tacit conviction that dialogic pedagogy can be studied exclusively or even principally through discourse analysis. In gist, we claim that dialogue, and especially authorial ontological dialogue, involves and is defined by the participants' authorship of meaning. Thus, we argue that the key for studying dialogic pedagogy should be dialogic analysis of authorial meaning making (i.e., the authorship of meaning making based on people's unique and diverse voices in dialogue), based on particular concerns and attractions by the participants. We argue that authorial meaning can be studied only in a dialogue through and with other authorial meaning about their concerns, observations, interests, excitements, inquiries, values, and so on. Students' and teachers' educational authorship of meaning making can be mainly studied by and through the researchers' evaluative authorship of the original meaning-making by the researched embedded in a timeless Big Critical Dialogue, thus involving the researcher in further dialogues with both academic and educational community (and even beyond). Dialogic analysis is different from other kinds of qualitative analytic methods in that the researcher assumes an equal rights perspective to the studied meaning-making event, effectively positioning oneself as a participant in the primary dialogue, rather than as a final authority with a bird's-eye view or as opinions, juxtaposed among other opinions. Although discourse analysis can assist this process, it cannot lead the research.

We define discourse as a semiotic flow of signs signifying to the participants and observers what is salient for them in the situation while not being tangibly and physically present in it. The discourse signifiers may involve such material objects as dress, landscape, body shape, accent, words, intonations, the structure of interactive turns, gestures, behaviors (and its scripts), age, skin color, odor (or its absence), and so on (e.g., see a discourse analysis of the dress and manerisms of bikers at a bar to be accepted as a member of the bikers community, Gee, 2011). Discourse signified may involve such ephemeral and intangible aspects ${ }^{1}$ as history, class, gender, power, recognized types of relationship, sexual orientation, used speech genres, ideology, profession, family or community status, activity role, and so on.

In contrast, dialogue, involves a special quality of human relations, based on the principle of "a plurality of consciousnesses, with equal rights and each with its own world, [that] combine but are not merged in the unity of the event" (Bakhtin, 1999, p. 6). At the core of this (ontological) dialogue, argued Bakhtin, is authorship of meaning. Meaning is defined as a dialogic relationship between an interested question asked by one person and a serious reply by another person in a broader sense (Bakhtin, 1986). In genuine education, the questioning person is primarily the student, while the responding person may or may not be the teacher. In educational research guided by dialogic analysis, the questioning person is the researcher while the responding person is the researched, although in a critical dialogue of dialogic analysis they can easily switch their roles because in dialogic analysis, any authored meaning can become a subject of further questioning. In our view, this is what might be behind of "a plurality of consciousness, with equal rights" - a right to be questioned by the research participants and beyond.

We argue that all types of Discourse Analysis ${ }^{2}$ are mainly about recognizing structural and/or functional patterns of discourse - patterns that have some relevancy for the researchers (and, at times, beyond the research community). By "structural patterns," we mean a pattern of organization of some elements of the discourse like conversational turns, roles, power relations, mediational tools, rules, norms, semiotics, narrative structures, voices, linguistics elements (e.g., grammar, genres, registers), and so on.

\footnotetext{
${ }^{1}$ This is what probably Soviet philosopher Evald llyenkov unconventionally refers as "the ideal" (llyenkov, 2009).

${ }^{2}$ It can be interesting if a reader can find any exception from our claim.
} 
By "functional patterns" we mean a pattern of the relationship between outcomes/effects of the discourse and means responsible for these outcomes. Functional patterns of discourse may involve relational breakdown, agreement, disagreement, power domination, silencing, arriving at truth, recognition as a full member of a community or a group, decision making, arriving at preset curricular endpoint, doing "dialogic pedagogy," and so on. The studied structural-functional patterns can be preset or emergent in a discourse analysis. Trappes-Lomax (2004) discussed a diversity of linguistic and interdisciplinary Discourse Analysis,

Discourse analysis may, broadly speaking, be defined as the study of language viewed communicatively and/or of communication viewed linguistically. Any more detailed spelling out of such a definition typically involves reference to concepts of language in use, language above or beyond the sentence, language as meaning in interaction, and language in situational and cultural context. Depending on their particular convictions and affiliations - functionalism, structuralism, social interactionism, etc. - linguists will tend to emphasize one, or some, rather than others in this list (p. 135, the italics are original).

In our judgment, Discourse Analysis in all its all variations focuses on abstracting structural-functional patterns, while considering the very notions of "structural and functional patterns" broadly defined, beyond narrow definitions of structuralism and functionalism.

We claim that the birthmark of Discourse Analysis, as such, is to treat dialogue as it, as a thing among other things, as an object of analysis existing independently and outside of the researchers studying it, which can be viewed by well-informed and well-trained scholars in the same way (cf., "intercoder reliability"). Discourse Analysis objectifies the subjectivities of the participants by trying to eliminate the subjectivities of the researchers, and especially their authorial subjective judgments (of course, never successfully). Thus, Trappes-Lomax sees differences in researchers' subjectivities as a problem of validity to be solved using diverse methods,

One way of dealing with subjectivity is through multiplicity of approach. This is usually referred to as triangulation and is especially characteristic of ethnographic approaches. Triangulation is generally understood to refer to the use of different types or sources of data (for example a participant's account in addition to the analyst's account) as a means of cross-checking the validity of findings, but may also refer to multiple investigators, multiple theories, or multiple methods (Denzin, 1978), (Trappes-Lomax, 2004, p. 141).

In positivist-minded research, disagreements among researchers about perceived patterns of discourse have to be reconciled into agreements.

These attempts to take out the researchers' subjectivity are, in our view, attempts to take a bird'seye perspective on the given reality and to make it as pure as possible - even and especially when Discourse Analysis focuses on various issues of human relationships, perspectives and identities. Thus, for example, in his classical book on Discourse Analysis, James Gee defines it in the following way, "Discourse analysis considers how language, both spoken and written, enacts social and cultural perspectives and identities" (Gee, 2011, p. i). He claims that Discourse Analysis focuses on meaning, "The approach [to Discourse Analysis] in this book looks at meaning as an integration of ways of saying (informing), doing (action), and being (identity), and grammar as a set of tools to bring about this integration" (Gee, 2011, p. 8). In our judgment, Gee defines "meaning" monologically as a particular pattern that has the function of an integration of informing, doing, being, and "grammar of tools." Monologic "meaning" is always a pattern, a thing, which is often located in mediation, gestures, intonations, behaviors, actions, 
signs, words, sentences, utterances, networks, and systems. This pattern seeking is often related to a structuralist and/or functionalist approach to language use in a situated interaction, focusing on studying either structures of a discourse or functions it services for some activities or both. Linell (1998) describes it in the following way, although within the framework of "dialogism," which, in our view can be more accurately called "discursivism"3,

Discourse and discursive practices are themselves highly structured. It is possible to generalize across singular situations to define patterns, sequential structures, routines, recurrent strategies and situation definitions (framings), activity types and communicative genres, as well as more traditional linguistic unit and rules. But this is largely structure within discursive practices, rather than structure apart from, above and before discourse. Moreover, it is first and foremost an organization of social actions, and not a structure pertaining exclusively to language and linguistic forms. This is of course not to deny that there is a formal structure of e.g. the syntax of spoken language as it appears in actual discourse. Within a comprehensive dialogism, structuralist and functionalist perspectives could penetrate and complement each other (Linell, 1998, p. 5, italics are in original).

In Discourse Analysis, monologic "meaning" is a semiotic thing, a semiotic pattern. Thus, Gee (2011, pp. 8-10) exemplifies the discursive "meaning" by two sentences about hornworms showing that one sentence belongs to an everyday discourse, shaped by certain cultural practices, while the other belongs to a scientific biological discourse, shaped by (positivist) science practice. Gee convincingly argues that these two discourses generate different functional patterns of integration of informing, doing, and being i.e., different discursive "meanings" (or better to say functions). Essentially, espoused Discourse Analysis equates "meaning" with a particular pattern recognition. Of course, in practice Discourse Analysis also usually involves dialogic meaning-making of the recognized structural-functional patterns as well. It often has genuinely interested inquiries and question addressing, at least, the academic community, in which this Discourse Analysis is situated. It is often guided by the researchers' own genuine emerging interest, redefining their initial inquiries and questions. Discourse Analysis researchers often try to make sense of the new patterns they find and consider their implications. However, Discourse Analysis researchers often feel uneasy with their own dialogic meaning making because it undermines the objectivity, generalizability, and validity of their research by positioning the researchers as subjective unique authors of their dialogic meaning making rather than as objective scholars of a given reality (Denzin \& Lincoln, 2005).

When Discourse Analysis is used to study dialogic pedagogy, it focuses on looking for, identifying, and coding certain structural and/or functional patterns that are attributed to dialogic pedagogy by the researchers. These (mostly) functional patterns might involve "dialogic instruction," "dialogic enquiry," "dialogic teaching," "heteroglossia," "intertextuality" (or "heterodiscursia"), "high students-teacher talk ratio," "asking open-ended questions," "the teacher's uptake of student ideas," "cycles of critique," and so on,

Drawing mainly on the theoretical ideas of Bakhtin on the dialogic nature of language, a number of authors have stressed the educative potential of teacher-student interaction which enables students to play an active part in shaping the agenda of classroom discourse. Examples include: dialogic instruction, characterised by the teacher's uptake of student ideas, authentic questions and the opportunity for students to modify the topic (Nystrand, 1997); dialogic enquiry, which stresses the potential of collaborative group work and peer assistance to promote mutually responsive learning in the zone of proximal development (Wells, 1999); dialogical pedagogy, in which students are invited to retell stories in their own words, using paraphrase, speculation and counter-fictional utterances

\footnotetext{
${ }^{3}$ However, Per Linell (personal communication, December 2018) does not agree with our characterization of his approach.
} 
(Skidmore, 2000); and dialogic teaching, which is collective, reciprocal, supportive, cumulative and purposeful (Alexander, 2004) (Skidmore, 2016, p. 98, the italics are original).

These structural-functional patterns of the studied students-teacher classroom discourse are both conceptualized and operationalized to be coded for presence or absence the listed structural-functional patterns of dialogic pedagogy. What is important for our discussion here is that researchers of Discourse Analysis do not need to participate with their mind and heart in the ideas discussed by the research participants beyond the coding, interpretation of findings, and making implications, which often involves a minimum of their ontological engagement with the ideas raised in the studied discourse and a minimum of their dialogic contact with their research participants. Researchers' participation with their heart and mind in the studied phenomenon (i.e., ontological engagement) means reporting the researchers' personal feelings, authorial thoughts, personal experiences, personal connections, authorial descriptions, and authorial judgments in a response to the observed phenomenon and the research participants' contributions (Matusov et al., 2019, in press). Discourse Analysis researchers do not usually engage in addressing or replying to the research participants, at least not in an explicit and legitimate way. They are often not in a dialogic ontological contact with them, neither intellectually nor emotionally.

In contrast, in Dialogic Analysis, researchers are active co-participants in the dialogue with the researched participants and their ideas. The data collection process adopts dialogical approach (Sullivan, 2011) which attempts to form dialogues among the participants as well as between the participants and researchers to explore the research question. Sullivan wrote that dialogical approach is concerned with the subjectivity of data analysis. This approach takes Bakhtin's $(1986,1999)$ perspective that "ideas are exchanged but ideas are actually lived rather than abstract and are full of personal values and judgements" (Sullivan, 2011, p. 2), which attempts to form dialogues among the participants as well as between the participants and researchers to explore the research question.

In this article we present, analyze, and compare dialogic analysis and discourse analysis. We first focus on an existing dialogic analysis study of a dialogic lesson in science with first-grade children discussing gravity by Hammer and van Zee (2006), that we define as a case of "tired gravity", Case \#1. In the process of our dialogic re-analysis of this pedagogical event, we enter into agreements and disagreements with the original researchers, David Hammer and Emily van Zee. We express puzzlements and have many questions for them and for the first-grade teacher whose science education class was recorded and described by them.

Next we present and dialogically re-analyze two cases presented by David Skidmore (2000) as cases of Discourse Analyses (Cases \#2 and \#3). One of the cases (Case\#2) represents Skidmore's discourse analysis of monologic pedagogy in a language art lesson in a multicultural primary school where the teacher quizzed the students to determine how well they comprehended a story "Rocky's Fox." The other case (Case \#3) represents Skidmore's discourse analysis of dialogic pedagogy with the 5-6th grade students discussing their views about characters in a story "Blue Riding Hood," a parody of the "Red Riding Hood" that makes all the characters behave in rather questionable ways. In our subsequent dialogic reanalysis of these cases, we discuss the appropriateness and the limits of discourse analysis as predominantly searching for structural-functional patterns in the classroom discourses. We discuss dialogic tensions in the reported dialogues that cannot be captured by discourse analysis search for patterns. We question David Skidmore's conclusions about dialogicity of the Case\#3, based solely on the discursive patterns that are coded as dialogic, without entering into the critical dialogue about authorial meaningmaking between the teacher and the students and about the discussed story. 
Throughout our dialogic analyses of all three cases, we address the teachers, the researchers (the authors of the cases), the involved children (students), and the discussed texts/ideas (and their authors). We also entered into dialogic disagreements amongst ourselves, when we, the four authors, have differences in interpreting transcripts, or question each other's views of what was happening in that class and what we think it all meant to the teaches and different children. And we invite the readers to join us in this dialogue - we are looking forward for our future readers' replies to this paper.

We conclude the article with presenting our new questions, quandaries, agreements and differences among ourselves (the authors) about dialogic and discourse analysis. This unfinalized, still open, nature of the research conclusions marks this research as uniquely dialogical and distinguishes it from other qualitative research which also recognize personal meanings ${ }^{4}$.

\section{Dialogic analysis: Case\#1 of "tired gravity"}

As an example of dialogic analysis, we chose a case of "tired gravity" from a terrific book "Seeing Science" by David Hammer and Emily van Zee (2006) describing, analyzing, and promoting dialogic pedagogy in science education. The book includes many lessons ${ }^{5}$ of teachers of diverse grades involving their students in deep, more or less free, conversations about diverse physical phenomena. The lessons were then presented to teachers during professional development workshops to "see science" in the students' free conversations. The researchers also interviewed the author teachers about their lessons and their decision making. The main goal of both the research and pedagogical practices described in the book was to promote professional dialogues among teachers and to recognize and imagine new teachinglearning opportunities, rather than to criticize author teachers. Hammer and van Zee argued in the book that the major problem of traditional science education (and probably beyond) is failing to recognize science in students' everyday thinking and conversations about natural phenomena. With a reference to Albert Einstein, they define science as refined discursive thinking on possible mechanisms - "tangible causes and effects" (p. 6) - behind natural phenomena.

The entire case of "tired gravity" in the first-grade classroom took exactly the first 9 minutes of the Day\#2 lesson (21 minutes total on the video accompanied with the book). Paradoxically, it was the most prominent "case" in Ana's and Eugene's reading of the book. We wrote, "paradoxically" because, arguably, this "case" was the least developed by Hammer and van Zee, who skipped it in most of their workshop seminars, "In almost all seminars we skip this segment, in order to get to what comes later. It is mostly made up of the teacher trying the experiment herself in front of the children. At the end there's some joking about how 'maybe the gravity's tired' (lines 212-25), which could be interesting to think about. What's the joke? What understanding goes into making it or finding it amusing?" (p. 90).

However, David Hammer and Emily van Zee seem to be clearly intrigued with this case, since they actually keep referring to it in their introductory chapters. The "tired gravity" and what the teacher, was doing to guide the children, attracted a lot of attention, but at the same time it seems that it was rather confusing and made David and Emily not sure what to do with it. David and Emily, we wonder what the teachers said about it when Hammer and van Zee presented it in a few workshop-seminars. This episode has initially become a case of interest for me (Matusov, 2018b) and then for the other authors of this article. We respectfully disagree with David Hammer and Emily van Zee's interpretation that the episode can be reduced to the teacher's demonstration followed by the children's joke. We were also attracted and even fascinated by the author teacher's immediate reflection on her decision making during the episode (p. 78)

\footnotetext{
${ }^{4}$ We are thankful Tara Ratnam for making this point clear for us.

5 The book came with videos of the lessons and their transcripts.
} 
and then her postponed, arguably contradictory, profound reflection promoted by her later conversations with other teachers (p. 78) (see below). Question for David, Emily, and the teacher, what were these conversations about? Do you remember? As a former schoolteacher of physics, a dialogic pedagogy educator, and a scholar of dialogic pedagogy, I (Eugene Matusov) immediately recognized an importance and richness of this dramatic dialogic event that I conceptualized as first the teacher inviting her students for a genuine dialogue, then silencing them, and then critically rethinking her guidance. The other three authors of this paper agreed. Elsewhere, my second author here (Ana Marjanovic-Shane), some other colleagues, practitioners and scholars of dialogic pedagogy, and I developed a research on "idea-dying out" in dialogic pedagogy, in which we studied cases when students' ideas were extinguished in a classroom discussion (Marjanovic-Shane, Meacham, Choi, Lopez, \& Matusov, 2019). We (the first and second authors) think that the case of "tired gravity" belongs to this phenomenon of the teacher's silencing the children's ongoing dialogue.

So, why did we choose this particular case to illustrate and engage our readers in dialogic analysis of dialogic pedagogy? We have the following three main reasons. First, the case generates a strong excitement in all of us. Usually, it is so difficult to find a teaching case where a teacher allows students to speak freely and listens to them very carefully and mindfully. We also had a strong desire to discuss it among ourselves and with David Hammer, Emily van Zee, dialogic researchers of dialogic pedagogy, with whom we both agree and disagree and with the author-teacher, whose contradictory and creative reflections we found very thought provoking. In other words, this case powerfully "sucks" us into a dialogic analysis of dialogic pedagogy and hopefully we will be able to promote engagement of our readers in it. Second, in contrast to more developed cases of dialogic analysis such as, for example, by Joe Tobin and his colleagues in their project "Preschool in three cultures: Japan, China, and the US" (Tobin, Davidson, \& Wu, 1989; Tobin, Hsueh, \& Karasawa, 2009), Hammer and van Zee focused on a) dialogic pedagogy (in their version) and b) academic curriculum and instruction. Arguably, the most attractive cases (for us) of dialogic analysis by Tobin focused on a) conventional pedagogy and b) classroom management. Third, the case of "tired gravity" is at par with David Skidmore's Cases \#2 and \#3 (see below) of discourse analysis involving elementary school students. Now we turn to providing a description and our interpretation and critical meaning making of the case.

On the day \#2 of the "Falling Objects" lesson in the first grade, the teacher started her lesson asking her students to report about their experiments with a falling sheet of paper versus a falling book from the same height letting them fall at the same time. The students were very enthusiastic to reply providing all possible answers the outcome of the experiment ${ }^{6}$ :

1 Teacher: What, what happened when you dropped the book and the piece of paper at the same time, at the same height? Huh, what happened? [Students raising hands] OK, Ebony, why don't you go ahead and begin...

$[\ldots]$

4 Ebony: To $\mathrm{me}^{7}$, first, the paper fell first.

\footnotetext{
${ }^{6}$ The following fragments are from Hammer and van Zee (2006) book's accompanying appendix of transcripts of the lessons. For the most part we summarize the teacher's and the children's dialogue, but we tried to preserve the actual voices directly quoting them, when absolutely important for our dialogic analysis. For the full transcript see Hammer and van Zee (2006). Since the book is accompanied with DVD with the videotaped lessons, we enriched some of the transcribed verbal contributions by adding descriptions of non-verbal communication in the presented transcript. They are marked with the italics.

${ }^{7}$ Bold is ours. We made some text bold to highlight issues we later discuss, so that the reader can easily be guided to the actual parts of the dialogue that we refer to in our analyses.
} 
Several children, Jorge, Brianna, and Henok, disputed Ebony's claim, insisting that to them the book fell first. To each one of them, Ebony replied that $(11)^{8}$ " $\ldots$ the paper fell first to me!" The children continued asking Ebony what happened to him and telling each other what happened to them. Jorge asked if that the book fell first, or the book and the paper fell at the same time. Ebony insisted that for him the paper fell first. Henok and Ebony had a small dispute about what fell first, Ebony claiming that it was paper. At one moment, Allison addressed the teacher telling her that, (18) "to Ebony the paper fell first." But the teacher let the children's dialogue continue without replying to Allison. Most of the students disagreed with Ebony, claiming that the book fell first. At one point, Jorge said, (22) "Our paper-our paper goes slowly. It's, it's, it's a little bit [out of practice?]." Rachell added that for her and Julio the book and the paper were tied twice. Ebony, Allison and Rachel had a small side discussion about what it means to be "tied." Ebony and some other students clarified that it meant the paper and the book fell at the same time. Allison emphatically agreed that it was the same case with her, exclaiming "same with me!" four times.

At that point the joint group discussion disintegrated into smaller groups and pairs who created parallel dialogues creating inaudible noise and laughter. The teacher called their attention saying,

36 Teacher: So, what I'm hearing is that we have one person that said when he did it, that - [...] - that when he dropped at the same time, from the same height-

40 Brianna: The paper fell first

41 Teacher: [turning to Ebony] — that the paper fell first. Now do you mean it hit the ground first, or it just started to fall first?

43 Ebony: It hit the ground first.

44 Teacher: So, you're saying the paper hit the ground first, and then the book hit the ground. [Ebony nods his head in affirmation.] Then we have two other friends who are saying that the book and the paper hit the ground at the same time.

48 Rachel: Twice!

49 Students: Yeah! Twice!

50 Teacher: Twice. You did it twice and that's what you noticed.

51 Allison: Yeah, me too!

52 Teacher: OK.

The teacher established firmly for herself and the students that the students claimed to have observed three different outcomes of the experiment with the falling paper and book: 1) for Ebony, the paper fell before the book, 2) for Brianna, the book fell first, and 3) for Rachel, the paper and the book reached the floor at the same time. The teacher then moved to the problematization of why different "friends" (i.e., students) obtained different results of the same experiment.

73 Teacher: How could this be that we all did the same thing -we dropped the paper and the book-

75 Brianna: And it was all different!

[...]

77 Teacher: - at the same place, at the same time. How could it be that we got all these different results? One person found out the paper hit the ground first, and then the book. We have two other friends that found out the book and paper fell down at the same time.

\footnotetext{
${ }^{8}$ We use the numbers in parentheses in the in-line quotes, to indicate the line numbers in the original transcript. When directly quoting the transcript, we preserved the formatting without the parentheses.
} 
For a while, the students and the teacher continued to discuss the different results children got, until the teacher asked, (73-77) "How could it be that we all— we got different results— $[\ldots]$ - when we did the same thing?"

Analyzing this event, we (the authors of this article) had different interpretations of what was going on at this point. We decided to preserve our authorial discussion in which we questioned and challenged each other's interpretations. Below we present it and extend an open invitation to the reader as well.

Tina Kullenberg: It is interesting that these key words "How could this be" by the teacher are to be repeatedly found in lines $77 \& 86$. I am not sure of how dialogic this particular question really is. Whether it is a teacher-like rhetorical question or not. If the teacher is searching for a correct, pregiven answer (according to the scientific laws in this case) or it could be conceived of as a genuine, explorative question.

Eugene Matusov: Dear Tina, my reading of this that the teacher sincerely believed in the moment that getting different results of "the same experiment" is impossible. I think her question and her search for possible plausible explanations of the phenomenon experienced by the children are genuine. I do not think that she tried to make the students to arrive at a preset curricular endpoint.

Ana Marjanovic-Shane: I am unsure whether to agree with you, Tina, or with you, Eugene, that in the case of "How could this be" question, the teacher is trying to swing the children toward a preset scientific understanding of gravity, thus not being genuinely interested in their answers, or if she is genuinely puzzled with different results in "the same experiment." I kind of think that the teacher was fluctuating in her being genuinely dialogic (like in 41-44 -where she is asking Ebony to explain what he meant by "fell first"; and when she is carefully mirroring the students' reports and summarizing differences in among them); and being herself sure in her own understanding of gravity, rather than actually trying to conceptualize what the students' concepts of gravity might be. This is why it sometimes looks to me as if she is genuinely interested in the children's dialogic opinions, and sometimes she seems to be just sure that her understanding of the science of gravity is the only possible, correct way of conceptualizing these forces.

I think that we see these two different aspects of this teacher in her genuine struggle to be dialogic, and in her approach to science.

Tina: I see what you mean, Eugene. I am not quite sure about my own opinion yet but will take a closer look on it. However, Ana, I really liked your added reflections here. The teacher perhaps was wondering this genuinely, so to speak, but what is even more important is her approach to the voices of the others, namely the children's own understandings of the phenomenon. To mirror their ideas and clarify different viewpoints among them without sincerely letting these viewpoints affect your own interpretations is not completely dialogic? (Also in monologic scaffolding you are mirroring and answering prompting questions like that, no?)

Kelly Curtis: I think these are all interesting points. I like Tina's point about getting at students' understanding of the phenomenon, in their own words. When I read "how could this be" I was wondering if she was pressing students to reflect the conditions of the experiment. For example, perhaps the students did not all drop it in the same way. She summarizes what the students said, "fell first," meant by reiterating, "at the same place, at the same time." Perhaps she was trying to prompt students to talk about someone not letting go of the objects at exactly the same time. In this way, I agree with Eugene that the teacher believed that students should have had similar results. 
$\leq<$ Tara Ratnam, feedback 2019-02-06: This classroom episode poses a tricky situation for readers' interpretation: On the one hand there is a preset/given understanding of gravity. In that sense ultimately the teacher's intention might be to lead them towards that (Here, I tend to agree with Tina's point about monologic scaffolding). On the other hand, if you look at the classroom interaction per se, it can be seen as an opportune opening to furthering an understanding of a phenomenon in the dialogue of differences in probing the students' subjective experiences further.>

It seemed that the teacher decided to focus the children on searching for a physical mechanism that could explain their striking different outcomes of their experiment, conducted in the same way (as the teacher claimed). The students seem to struggle for an explanation, by first trying to retell their experiences: for some of them, in some turns, the book fell first, but in other turns the paper fell first. The teacher continued to solicit their opinions on what happened and why, until one child, Rachel, suggested that the reason is in the "forces of gravity." Another child, Diamond, asked for an explanation of what "forces of gravity" are. Various children gave different answers: that gravity is what "keeps us down on the ground" when we jump, like "ground magnets," that there is no gravity in space where one can "never fall down," but just "float in the air," and so on. Some children started demonstrating it by jumping and showing how gravity pulls them down. When more children got up to jump and laugh, the teacher said, (turn 121) "Oh, we're not all going to [jump?]." and directed the children to sit down. The teacher then restarted the dialogue about the force of gravity:

129 Teacher: So, you're sayin' the force of gravity is pulling the book down at a different time than the paper.

131 Student: Yeah.

132 Rachel: Yeah, probably. And, sometimes it's pulling it down at the same time, or pulling the paper down-

134 Alison or Brianna[?]: Before the book.

135 Brianna[?]: And then the book, and then the paper [?]-

136 Rachel: - before the book and then the book's pulling it down before the paper. Gravity's pulling the book down before the paper.

The teacher then carefully guided the children's attention to a puzzle of getting different results in their experiments, asking, (139) "Why would gravity-why would gravity? [Three-second pause] How do I phrase this. Why, why would gravity sometimes make the book come down first, and then the paper. But the, the same gravity at other times make things come down at the same time. Or you're saying that gravity sometimes makes the paper come down before the book. ... Why does-why does gravity do all the - l'm trying to think. [Two-second pause] How could gravity make-how could the same force of gravity... give us three different results?"

The children again seemed puzzled and started to describe what happened in their experiments. The teacher guided them with a lot of supporting questions to remember whether they dropped the paper or the book first, or together. A child, Henry was deeply involved in testing his ideas about what happens if you drop the book and the paper together. At one point his idea was that, (167) "... if you, if you drop 'em at the same time, maybe they might fall on the same time-on the floor."

The teacher announced that she was going to demonstrate what happens by dropping the paper and the book together three times and asked the children to watch and see what happens. When Diamond offered a hypothesis, the teacher dismissed it and said, (174) "Well, we'll see. Some people said that that's 
what they found out, other people that they saw that they hit at the same time, and then we had two people that said that 'well, the paper hit first.' Let's see what happens, OK? You guys watchin'?"

The teacher started dropping the paper and the book together. Every time, when the book dropped first, some children exclaimed in confirmation that they "knew it." After the third time, there was some laughter and a boy, Henok turned to Ebony saying, "See, Ebony?" Then the teacher looked at Ebony and said,

197 Teacher: But, you found out something different.

198 Ebony [nods]: The book-the paper fell first.

199 Teacher: How could that be?

200 Ebony: I don't know. [Ebony shrugs his shoulders.]

The children were still puzzled. Autumn alleged that Ebony possibly dropped the paper first, but Ebony denied it. Then Allison offered another hypothesis (207) "一the gravity probably had, uh, [turns to Ebony] the gravity probably just pulled the paper a little more than it pulled the, the, um, book." Ebony responded to that with a laugh, (209) "Maybe it's tired."

This made almost all students laugh and repeat "maybe the book is tired." The teacher joined the children's laughter for a while, but then she stopped and said, (216) "Let's come back to Allison's idea. Allison said, 'Well, maybe the gravity - the time when Ebony did the gravity pulled the paper down more than the book that time."'

However, instead of following the teacher, Ebony laughingly repeated his joke that the gravity is maybe tired. Many children exuberantly joined him. Autumn leaned towards the teacher, very close to her, eagerly waving and smiling to her, and repeated Ebony's joke about "tired gravity."

But the teacher announced a change of the activity, (223) "We're going to do something different now with the piece of paper; watch this." The students continued for a while to make comments about gravity being tired. Allison continued a discussion with Ebony, about gravity pulling something faster than something else, using hand gestures to represent each object. The teacher continued with the change of the activity, (228) "When you go back to your seat, this is what you're, you are going to do with your piece of paper." She crumples up a piece of paper...

The teacher now chose to not be responsive to Autumn, who was explicitly echoing the joke that the gravity was tired. Instead, the teacher demonstratively turned her face and body away from Autumn and introduced the next activity on the agenda, shifting the conversation to another phenomenon: the crumpled piece of paper falling down at the same time as the book. No more discussion of why the children reached different outcomes by letting a straight piece of paper and a book to fall down. No more discussion of variable and unstable gravity. No more discussion of tired gravity. No more joking. Back to serious exploration of the physical mechanisms and the instructional agenda.

Tina: To me it is feels that the teacher somehow speaks in terms of "discovery" and "exploration." But I think she does it for the sake of persuasion; the aim of giving evidence for the universal physical law?

Eugene: Again, I respectfully disagree with you, Tina. I think that the teacher was sincere here - in my view, she sincerely exhausted her attempts to engage the students in exploration of "mechanisms" and 
she did not know what to do with the diverse outcomes of the experiments and with the "tired gravity" joke. She got stuck and wanted to move on. What do you think?

Tina: Eugene, then I would say sincere persuasion. After viewing the video and reading the transcriptions, I do not have the impression that the teacher is teaching and talking in an openended, non-finalizing way to the children. In my eyes, she orients to a consensual "agreementdiscourse", seeking to unifying the voices in the end, according to her scientific and pedagogic believes. In doing so, she mirrors and clarifies different student viewpoints and experimental outcomes, no?

Ana: I am listening to the teacher in turn 216:

Teacher: [Laughs with the students] Let's come back to Allison's idea. Allison said, "Well, maybe the gravity - the time when Ebony did the gravity pulled the paper down more than the book that time."

To me (sic!), it sounds like the teacher is sincerely trying to "hunt" for children's ideas and mirror them back to children, in order to provoke more discussion. And yet, she still cannot figure out what to do with some of their dialogic turns: I think she struggles to interpret what the expression "tired gravity" was meant to do and what it really did. I think that she herself is wondering was it a joke, or somehow a genuine idea about how gravity might work. I think that she was not insincere, or manipulating, but because she herself was somewhat confused about the intent of the "tired gravity" that children themselves laughed about, she decided to retreat to a safer ground of "scientific experiments" (see her subsequent explanation in the quote below.) What do you think? Especially, you, teacher, and you, David and Emily, what do you think?

Tina: Ana, I also think she is somehow seeking for the children's ideas and making them explicit in order to provoke further discussion. However, what I was referring to more specifically is the ultimate purpose of this kind of classroom discussion (as I interpret her, of course I would like to hear her own opinion here). In this particular case, the teacher seems to refer to Allison's suggestion of a scientific principle that she (Allison) herself was after. Therefore, the teacher had a plausible reason to re-contextualize Allison's claim again. In doing so she argues for her own opinion via support from Allison's "correct" reasoning. Utilizing Allison's comment as a resource for herself is at least partially finalizing teaching? What do you think about such an interpretation?

Kelly: Tina, this makes me wonder what the teacher's opinion of gravity is then. When Galileo dropped two spheres of different masses off the Leaning Tower of Pisa, he demonstrated that the objects would fall for the same amount of time. Therefore, from my perspective, gravity "pulls" on objects the same amount. The issue with the paper versus the textbook has more to do with air resistance than with gravity then. But perhaps the teacher was allowing students to explore the idea of gravity pulling on the book "more" in preparation for the next experiment when they crumple the paper into a ball and perform the experiment again. This experiment would contradict their conclusion that gravity pulls more on heavier objects. I wonder if the teacher made the connection between the two activities, where in the first activity the book would drop first but in the second activity they would drop at the same time. This connection would influence how the teacher talked about the activity with the children. 
We judge ${ }^{9}$ this event as "idea-dying out" (actually "ideas-dying out") (Marjanovic-Shane et al., 2019) through the teacher's silencing the students. The teacher "killed" the dialogue about inconsistency of the experiment's results and the children's explanation through "tired gravity" by moving the discussion on to another topic, another physical phenomenon, and another inquiry.

$<<$ Tara Ratnam, feedback 2019-02-06: I tend to agree here [with your judgment characterizing the event as "idea-dying out"]. I don't see the point of opening to a dialogue the teacher initiated by the experiment she set for students who came up with diverse results. She didn't follow it through by allowing students to experiment and explore further to reach new levels of understanding. She also let go of her own contribution that could provide another perspective for students to juggle with in advancing their thinking. The potential to learn from differences was given an abrupt stop! However, this might not stop students from continuing to think /argue about it further beyond the class. In this sense there is still some value in the exercise the teacher set for students and the puzzling differences that it brought out.>>

The teacher seemed to disagree with us, at least, immediately after her lesson (she might agree with us later when she started seeing a possible physical mechanism behind the children's "tired gravity" joke). This is how the author teacher explained her pedagogical and organizational decision to switch the topic of the classroom discussion,

At this point, the students were out of ideas - perhaps out of steam. Or maybe they were confused by my asking them about an inconsistency that they did not see. In any case, I did not feel many of the students were comfortable with this explanation. The mechanisms they had talked about during their predictions, that the book would be pulled harder to the ground and that the air would push up on the paper, still seemed the most tangible explanations they had, and I wanted to get back to them. Since it looked like the class was tiring out, I decided to drop the book and flat piece of paper in front of the whole group, hoping to generate more discussion. It did not work. Instead, the students became a little silly, talking and giggling about how the book and the gravity were getting "tired." ... It was time to move on. (Hammer \& van Zee, 2006, p. 78).

Tina: I think this utterance, "At this point, the students were out of ideas - perhaps out of steam", is perhaps one of the most remarkable (and central) reasoning, worth to problematize because I cannot find evidence for it at all in the transcription. On the contrary, to me it seems like the children have a flow of ideas, although not the expected ideas, and they are using joking/humor as a childish, playful way of engaging in learning (I see it in a study of my own right now!). At least in my eyes. Do you think it looks like they are running out of ideas, tired and out of steam?

9 Tina: Or interpret? It could sound too harsh to the reader with the word "judge"??

Eugene: Sorry, Tina. This is pure judgment and not just interpretation. I know that middle-class folks do not like strong words and prefer euphemisms $(-)$. But feel free to explain of why you think that "judgment" is inaccurate descriptor of our (or mine only?) action here?

Ana: I agree with Eugene that what we are doing is not just interpretation, but our judgment is based on our interpretation. This may be a dialogic finalizing - a provocation to the addressed teacher to respond to our judgment.

Tina: OK, it could be my lack of language skill as well. In Swedish it is a strong value-based term. I was thinking about general readers. What do the term "judge" mean to you then?

Eugene: I think your Swedish understanding is probably correct. For me, "judgment," or better to say, authorial judgment, is making a subjective value-laden evaluative opinion about a phenomenon or a deed, for which the author of the judgment takes responsibility. I am against the Christian call not to judge other people. I think authorial judgments are unavoidable and important to make especially when they are highly dialogic. In itself, an authorial judgment is a deed, putting its author on record and on line of judgments by others. What do you think? 
Eugene: I think this was the teacher's interpretation at the moment of the lesson. Later, she seemed to disagree with her initial judgment, but it was not stated explicitly in the book.

Ana: Tina, I agree that the children were having a lively flow of ideas - but the teacher interpreted it different!! See the quote of hers. On another note - about our own disagreements and misunderstandings: It seems to me that it is sometimes hard to follow whose voice is saying what - since we all refer constantly to someone else's voice! I am not sure if this is possible to untangle - or is it just the really complex nature of our analysis.

Tina: Ana, your first point: yes, exactly! This is intriguing and worth to notice: that the children in fact have a vital web of ideas but the teacher did not seem to value it during the lesson.

Kelly: I agree and find it interesting that humor and laughter is a sign for some teachers that the lesson is getting off track when, in this case as Tina noted, the children are having a flow of ideas. I think this reflects the issue of the teacher dealing with classroom management that was mentioned previously in this paper. Generally, students are seen as "on task" when they are serious in how they are discussing ideas and seen as "off task" when they are acting "silly" and using humor. As Tina points out, when the children continue laughing about "tired gravity" (lines 209-222), the teacher tries to redirect the children to engage more seriously by making the transition in line 223, "We're going to do something different now with the piece of paper..." This effectively ends the laughter.

$\leq<$ Tara Ratnam, feedback, 2019-02-06: Here, I don't agree with the teacher that students got silly or stuck. I think it is the teacher who missed seeing its potential for further exploration. I am in the field observing/participating in preservice teachers' 'simulation lessons'. Time after time l've seen student teachers simply letting go of students' diverse ideas. For most part, they just allow students to say what they think and where it supports their (student teachers') point, they pick it up. The rest fall by the wayside. In a physics class (in the introductory part for a lesson on Newton's first law), to a question what happens if the bus you are traveling in suddenly breaks, there were three different answers, "I fall forward", I fall backwards" and I fall forward first and then backwards". The teacher went on to the next question she had planned to ask without stopping to problematise why 3 students spoke differently of experiences of the same phenomenon.>>

For the teacher, the students were simply tired or got stuck with the inquiry, "It was time to move on." On the one hand, we agree with the author teacher that it may be OK "to move on" when students' ability to dialogue on an inquiry or a phenomenon is exhausted because of their intellectual, emotional, or attention ability. We also agree that the discussion might have been stuck here.

However, on the other hand, we suspect that it was the teacher who got stuck and not the students. For the teacher, variable and unstable gravity did not make sense during the lesson, as she admitted later. Also, it seemed to us, at that moment she did not know how to guide the children in their phenomenon of having three different outcomes for the same experiment. After having conversations with other teachers during seminars organized by David Hammer and Emily van Zee ${ }^{10}$, the teacher seemed to have a second thought,

It sounded as though Rachel [lines 128-137] thought the force of gravity was a variable that acted according to its own whims, and my sense at the time was that this did not seem like a reasonable explanation.

\footnotetext{
${ }^{10}$ David, Emily, and Teacher, is it true or Teacher's conversations with other teachers were outside of the seminars? If the latter, Teacher, can you elaborate, please?
} 
But conversations later with other teachers gave me more to think about. Maybe Rachel was being more reasonable than I thought. She might have been thinking about how other things in nature have a varying effect, such as the wind: If you threw a ball from the same spot, in the same direction, at the same speed over and over again, the ball would not land in the same exact place every time. The wind might change speed or direction, causing the ball to take a slightly different course each time. Of course, the ball would probably land in the same place a few times, just like the book and the paper hit the ground at the same time more than once. Thinking about her idea in relation to this example made sense to me, so maybe it could be a reasonable explanation for these first graders. Gravity changes just like wind changes. Earlier, when I had asked them directly to resolve gravity's inconsistent effect, it is a possibility that they did not answer because they did not see the inconsistency (Hammer \& van Zee, 2006, p. 78, bold is added by us).

In our view, the teacher's proposed "mechanism" explaining the observed three different outcomes of the same experiment with falling paper and book is brilliantly creative. We applaud to the teacher's intellectual move of finding a natural phenomenon that behaves similarly to Rachel's (and Allison's, and some other children's) suggestion that gravity may be whimsically unstable. We also love the teacher's new pedagogical and, even more important, dialogical approach of taking children's suggestions seriously rather than dismissing them as children being stuck, silly, and/or tired, exhausting their intellectual and attention abilities. Russian philosopher of dialogism Mikhail Bakhtin argued that genuine dialogue starts when the participants assume that all of them have consciousnesses with equal rights and begin to take each other seriously (Bakhtin, 1999, p. 6).

Here we want to add a note on the role of humor and laughter in classrooms. For instance, turn 226 from the transcript lead us to think that at least some, if not all, of the students were neither running out of steam nor of ideas at all. On the contrary, they (Allison and Ebony) continued to engage in a genuine dialogue, trying to explore the gravity mystery at depth. In doing so they communicated vividly both with words and bodily gestures when seeking to illustrate and creatively explain the issue of that day's lesson. When considering the video-documented sequence it is quite obvious that they did not look bored or stuck as they talked it through. It is also notable that this turn was preceded by a peer discussion and not a teacher-led question or comment about the joke: the tired gravity. That means that the humorous, perhaps "childish," talk did not distract them from involving in the intended school-science at the moment. Humor could be seen as the learners' way to deal with knowledge playfully and dialogically, rather than a break from productive learning. Thus, it does not exclude relevant learning, but rather disguises it in another language. Consequently, it could be argued that it may be problematic to dismiss young students' way of exploring by means of dialogic jokes as non-serious or inappropriate knowledge building. However, we argue that even if the students had purposefully desired to totally drop the topic about the gravity experiment, thereby switching to another topic, they should have the academic right to do so, at least for a while (Matusov \& Marjanovic-Shane, 2019).

It is interesting for us that in Hammer and van Zee's book, the two quotes of the teacher we brought above followed one after another in the reverse order to the order we gave them, and that they were left without any explicit dialogic responses to each other. We wonder if the teacher still thinks that her students became exhausted and confused, even after she found a possible new intellectual and pedagogical approach of how she could have moved the inquiry forward? Knowing what the teacher learned afterwards about wind as a model for unstable gravity, would she have switched the class discussion to another phenomenon or not? If so, why? If not, how might she proceed? How would she address the joke in the context of the wind mechanism? Would the joke about tired gravity emerge at all, in her view? We do not know. Teacher, David, and Emily, what do you think? 


\section{Four puzzling concerns}

After reading the case of tired gravity in Hammer and van Zee's book, we have developed four major related puzzles for them:

1. Why had the teacher interrupted the class discussion on the inconsistency of their experiments' outcomes, unstable gravity as a possible explanation of this inconsistency, and children's joke of "tired gravity" metaphorically capturing the essence of their "mechanism" for whimsical gravity (and even modeling a whimsical behavior)? Prompted by the teacher's own later reflection (see her second big quote above), we rejected her initial explanation of children being tired and confused (see her first big quote above). Rather we suspected that the teacher became epistemologically, pedagogically, and dialogically paralyzed and frustrated. But, if so, why? Teacher, what do you think?

2. Why didn't the teacher come up with the idea of wind modeling whimsical gravity proposed by Rachel? Why didn't the teacher recognize science behind it? Of course, there could be zillion reasons for a missed teaching-learning opportunity as David Hammer and Emily van Zee discussed in the book: the teacher's lack of creativity in the moment, getting tired, being distracted by diverse multiple demands at the moment, and so. However, we suspected that a systemic problem was looming even if other explanations were also applicable. We sensed that something in the teacher's pedagogical orientation trapped her and prevented her from seeing other possibilities at the moment. If so, what was it and why did it prevail? Teacher, David, and Emily, what do you think?

3. Why didn't the teacher's then-reflections (immediately after teaching) and her now-reflections (when writing the case and reflecting on it) explicitly address each other, when strong implicit contradictions existed between them, and especially because they closely followed each other on the same page of the book (p. 78)? We see contradictions in the then-teacher claiming that she abruptly switched the classroom topic discussion because the children were tired and confused and the now-teacher taking on Rachel's idea of unstable gravity seriously. This question is for both the authors of the book - David Hammer and Emily van Zee - and for the author teacher. It is possible that they either did not notice these disagreements, or they would disagree with us that the teacher's reflections contradicted each other. However, again, we suspect a deeper problem behind possible neglect or disagreement.

4. Finally, we wonder what we might do in this teacher's shoes as dialogic pedagogy educators (and researchers) being outside of the urgency of the moment in contrast to the teacher's situation.

Here we want to propose ideas addressing all four of our puzzles for the readers' judgments and further discussions.

We suspect that a major meta-problem of the case of "tired gravity" is rooted in the authors' understanding of science as "refined thinking about mechanisms" behind natural phenomena (or human phenomena in social sciences). By "authors," we mean David Hammer, Emily van Zee, and the teacheras-author of this case. This view of science can be better understood in the light of the concepts of readymade science and science-in-action, developed by the French sociologist of science Bruno Latour (Latour, 1987, 1993, 1996, 1999; Latour \& Woolgar, 1979). Latour described ready-made science is a science without any or with only minimum human subjectivity. It is about the world how it is, independently of its observers and researchers. In contrast, science-in-action is a practice of cleaning out researchers' statements about studied phenomenon from researchers' subjectivity through a special discursive practice in a scientific community. Some readers may comment that Latour described a positivist science (positivist 
ready-made science and positivist science-in-action), which is a good point, in our view. However, school science is often, if not always, about teaching positivist science as well, positivist ready-made science, to be exact. Positivist ready-made science is about learning "facts" - statements of consensual truth, cleaned from any subjectivity, that Latour called "high modality statements" (e.g., "The Earth rotates around the Sun") (Latour, 1987). Traditional school with its monologic pedagogy focuses on imposing facts on students through monologic instruction and exams. The authors of the book, however, tried to get away from this approach by shifting from teaching ready-made science to engaging students in science-in-action guided by the teacher.

We see the problem in how, Hammer and van Zee, the authors of the book, defined the science practice as refined thinking about mechanisms. Namely, we see the problem as rooted in the authors' peculiar mixing of science-in-action with ready-made science practices. From the science-in-action approach, the authors have taken the discursive nature about science as a discourse of making mechanistic explanations through refining thinking about mechanisms in a dialogue. For instance, the teacher guides Brianna and others to refine and deepen their observations and reporting, in line 41 when the teacher replies to Ebony's statement, "The paper fell first" with, "Now do you mean it hit the ground first, or it just started to fall first?" The teacher creates two alternatives for Ebony's (and some other) children's discourse, introducing a possibility that they might perform their experiments differently, which results in different outcomes.

Also, along the same lines of evidence of dialogic pedagogy, the authors recognize, value, and promote authorial nature of students' creating mechanistic explanations. In contrast to conventional monologic pedagogy, the teacher and the researchers are not focused on making the students produce the correct explanations, but rather on the children's authorship of diverse explanations and testing them against each other. The teacher makes it important to acknowledge each child's observation, and contribution. For instance, the teacher replies to Ebony, "So, you're saying the paper hit the ground first, and then the book hit the ground. [Ebony nods his head in affirmation.] Then we have two other friends who are saying that the book and the paper hit the ground at the same time." and then acknowledges Rachel's and other children's remark "Twice!" by replying, "Twice. You did it twice and that's what you noticed." This promotes Allison to voice her authorship, "Yeah, me too!"

The teacher did not hunt for the correct answer, as many conventional teachers often do, but rather she hunted for students' creative authorial conceptualizations of mechanisms of the discussed physical phenomena. In our judgment, these two powerful aspects of science-in-action, discursivity and authorship, are embedded in the authors' defining science as refinement of thinking about mechanisms. Importantly, they constitute both dialogic pedagogy and the authors' dialogic analysis of this dialogic pedagogy.

However, we also argue that the authors' definition of science involves two aspects from readymade science and that exactly these two aspects created the problems in the case of tired gravity. The first aspect of ready-made science is about the insistence on the exclusion of human subjectivity from the science practice. The authors defined science as refining it from the students' thinking about mechanisms. They "forgot" Latour's discovery that the science-in-action practice primarily focuses on elimination of scientists' subjectivity from their explanations and facts. In the case of tired gravity, the children-scientists focused on emphasizing their scientist subjectivity rather than eliminating it. Thus, Ebony proclaimed, "To me, first, the paper fell first" (line 4). Ebony emphasized his scientist subjectivity via his intonation and then via his repetition (lines 8, 11, 13, 17), echoed by other scientists-children (lines 18-20, 22, 25, 34, 51). To us (sic!), Ebony and other scientists-children seemed to imply that a phenomenon can reveal itself differently for different people. Of course, this goes against positivist science-in-action studied by Latour. 
Scientists have to be disciplined to eliminate any subjectivity from their observations of a phenomenon. Correctly trained scientists must be mutually replaceable to experience and see the same thing from the same experiment. Thus, a part of (positivist) science-in-action is not only about creative generating, arguing, and testing mechanisms but also about eliminating their own subjectivity from their own observations and experiments. Interestingly, that at one point the teacher got apparently involved in discussing her scientistschildren's subjectivity to eliminate it through a consensus. Thus, on lines $36-37,39,41-42$, the teacher seemed to be checking if a problem of different outcomes of the experiment was rooted in a miscommunication, "So, what l'm hearing is that we have one person that said when he did it, that-...that when he dropped at the same time, from the same height_...-that the paper fell first. Now do you mean it hit the ground first, or it just started to fall first?" "It hit the ground first," replied Ebony. There is no miscommunication and the teacher moved to focus her scientists-students on finding a mechanism behind the discrepancy of the experiment outcomes.

In our meaning-making interpretation and analysis, the teacher's focus on generating and considering mechanisms as definition of science, insisted by the researchers David Hammer and Emily van Zee, partially blinded her from guiding her scientists-students sensitively and dialogically to explore their differences further and deeper. The question of how her scientists-students conducted their experiments seemed to be technical for the teacher, staying in the way of more important science actions of generating, arguing, and testing mechanisms.

In contrast, in our view, exploring differences is central for the science making. It is interesting for us that the teacher did not ask the students to show how exactly they conducted their experiments but throughout the lesson mostly did the experiments herself, with children occasional repeating what she did. On lines 86,88 , the teacher firmly closed the topic of the scientists-subjectivity by insisting that in their experiments, they all did the same thing, "How could it be that we all — we got different results- ... - when we did the same thing?" The question for the class became what natural mechanism could be responsible for diverse outcomes of their experiments rather than considering how and what they might have done differently while doing their experiments with falling paper and book. With their major focus on discourse about mechanisms, experimental science-in-action, full of human subjectivity that will be eventually eliminated to become ready-made science, was apparently not important, neither to the teacher, nor to the researchers. In fact, we argue, their focus on discourse about mechanisms contributed to an emergence of an epistemological and pedagogical trap for the teacher - to guide her scientists-students to imagine a natural mechanism behind the inconsistent outcomes of their experiments and away from the issue of how differently the scientists-students might have conducted their experiments.

The second ready-made science aspect, hidden in the authors' definition of science, is even more consequential and problematic in our view, than the first one, discussed above. The authors' definition of science as a refinement of everyday thinking about mechanisms of natural phenomena ${ }^{11}$ implies that the definition of science practice pre-exists the science practice itself. This is exactly the position of the readymade science described by Latour (1987). Aristotle labeled activities, which definition and goal pre-exist the activities themselves as "poïesis " (Aristotle, 2000). In contrast, in the science-in-action practice, its goal and definition emerge in the discourse of the community of relevant scientists, according to Latour's study. Aristotle called this type of activities "praxis." The teacher promotes and hunts for ready-made definition of science - namely, mechanisms, - while missing the whole discussion of the scientist subjectivity - "to me" - initiated by Ebony, as a scientific practice. Einstein's definition of science as a refinement of everyday

\footnotetext{
${ }^{11}$ Hammer and Zee (2006, p. 6) quoted Albert Einstein who said that, "The whole of science is nothing more than a refinement of everyday thinking" Einstein (1936, p. 349). They added focus of everyday thinking on mechanisms.
} 
thinking, Hammer's and van Zee's definition of science as thinking about mechanisms, Latour's definition of science(-in-action) as elimination of subjectivity ${ }^{12}$ are very interesting but still problematic and contested insights, in our view. For example, Latour's definition of science(-in-action) that reflects praxis of the elimination of researchers' subjectivity ${ }^{13}$ has been contested by quantum mechanics in general and by the famous Copenhagen interpretation approach formulated by Danish physicist Nils Bohr and by German physicist Werner Heisenberg in specific, arguing that elimination of the observer's subjectivity is impossible from a quantum phenomenon in principle (see, Heisenberg's principle of uncertainty), "There is no quantum world. There is only an abstract quantum mechanical description. It is wrong to think that the task of physics is to find out how nature is. Physics concerns what we can say about nature" (Nils Bohr, quoted in Kumar, 2008, electronic version). Thus, deciding what is science and what is "scientific" belongs to the scientific practice itself and to debates in a community of scientists while scientists engage in science, and does not pre-exist, or at least, does not fully pre-exist, the science practice. Science, science-in-action, is not poïesis but praxis. Or, in other words, using Bakhtin's neo-Kantian terminology, it is possible to say that in sciencein-action, the definition of science in unfinalizable (see, Nikulin, 2010).

We argue that the author-teacher's acceptance of the final definition of science, promoted by the educational researchers, severely limited her epistemological horizon, thus, preventing her to recognize emerging teaching-learning opportunities in the scientists-children's discourse. Even more, it robs the students from their own teaching-learning opportunities, not even mentioning their teacher's guidance. Thus, the "to me" discussion was abruptly put to the end when the teacher introduced her new inquiry, "How could this be that we all did the same thing - we dropped the paper and the book - ... - at the same place, at the same time. How could it be that we got all these different results? One person found out the paper hit the ground first, and then the book. We have two other friends that found out the book and paper fell down at the same time" (lines 73, 77-80). By implicitly making the diverse and personalized outcomes of the experiments strange and intellectually unacceptable, the teacher effectively closed a possibility for an inquiry, "Should we get the same results of the experiment or is it OK to have different results?" In everyday life, people are often faced with legitimately different perceptions, experiences, interpretations, meanings, and judgments while observing or being involved in a shared event. Probably, the best example of that is the Japanese 1950 movie by the director Akira Kurosawa "Rashomon" based on Ryåunosuke Akutagawa's short stories (Akutagawa \& Lippit, 1999). In the movie, the audience sees four different versions of a murderous crime that was perceived, experienced, and told by three participants of the crime and one hidden observer. The audience is left to think for themselves what "really" happened and whom to blame for the crime. Of course, in art, a diversity of subjective perceptions, outcomes, meanings, and judgments is very often legitimate and expected. In natural sciences, it is problematic, although not completely impossible in the Theory of Relativity or in Quantum Mechanics, while in social science it is open for a heated debate (Creswell, 2007; Denzin \& Lincoln, 2005). The author teacher could have engaged herself and promoted further the children's "to me" discourse and the inquiry behind it.

In few lines down the lesson, the teacher closed up another possible inquiry for the same reason of her epistemological horizon being severely limited by the preset definition of what science is about. As we already discussed above, on lines 86 - 88 the teacher shut down a possible inquiry of whether the scientists-children really do the same thing in their experiment or not. The author teacher apparently wanted to focus the children's attention on finding natural mechanisms that might be responsible for the differences

\footnotetext{
12 To be exact, Latour (1987) defines science-in-action as a communal discourse of changing modalities of scientists' statements about the studied world by elevating their own modalities into objective facts, independent of human subjectivity, and by downgrading modalities of their opponents' statements to subjective questionable falsehood ("artifacts" in his terminology).

${ }^{13}$ In our view, Latour has developed a model of poïesis of positivism (ready-made science) and a model of praxis of positivism (science-in-action).
} 
of the outcomes of their experiments with falling paper and book, while all of them "did the same thing" (line 88). Effectively, an inquiry of whether they actually did the same thing or not became blocked.

We wonder, when Rachel finally proposed a mechanism for the different outcomes of the experiment on lines $128-137$ by suggesting that gravity may act differently on paper and book at different times, if the author teacher took this suggestion seriously and pushed it forward by asking her scientistsstudents, "Why, why would gravity sometimes make the book come down first, and then the paper" (lines 139-143). However, in our judgment the teacher struggled to accept Rachel's mechanism as legitimate. The teacher apparently undermined Rachel's explanation by emphasizing "the same gravity" (lines 139143) and "the same force of gravity" (lines 145-147), tacitly rejecting Rachel's proposal. We suspect that the teacher struggled because she might have sensed the anthropomorphic nature of Rachel's mechanism. In our interpretation, the teacher struggled to formulate her question in a response to Rachel's proposal, "Why would gravity — why would gravity? [Three-second pause] How do I phrase this..." because she might have been trying to avoid anthropomorphism in her question and still "why would gravity sometimes make the book..." might have sounded as if gravity were a person. Her final formulation on line 147 was cleaned from any apparent anthropomorphism but at expense of firmly rejecting Rachel's mechanism, "how could the same force of gravity... give us three different results?" Only after conversations with other teachers, the teacher could see a possibility for a non-anthropomorphic mechanism behind Rachel's proposal unstable and apparently "whimsical" behavior of wind (see Hammer \& van Zee, 2006, p. 78, the quote is above). Again, according to our interpretation and analysis, the teacher's preconceived notions of what science is and what kind of mechanisms are legitimate severely limited her epistemological horizon and, thus, obstructed her recognition of emerging teaching-learning opportunities, injured her guidance, and, finally, inhibited students' critical dialogue.

Of course, we do not mean that if the teacher had not preconceived notions of science and mechanisms, she would have been able to recognize all teaching-learning opportunities emerging in the students' classroom discourse. We agree with David Hammer and Emily van Zee (2006) that it is impossible in principle. Teaching and learning are authorial and creative processes (Matusov, 2011). Our authorial approach to education is based on Bakhtin's authorial ontological and polyphonic approach to dialogic meaning making: an existential point of view that stands in sharp contrast to instrumental education (and instrumental educational research). On the instructional level, instrumental teaching designs imply standardized teaching "technology" where the participants' unique and creative voices tend to be neglected. Moreover, authorial teaching and learning might be considered as a "performance art" in which both the teachers and students develop critical voices which transcend the culturally given, such as pre-given norms, rules, conventions and fixed educational goals (cf. Matusov, ibid.). We don't think that this teacher's approach to teaching was instrumental. On the contrary, we think that she had a creative ontological, polyphonic and authorial approach to teaching. However, we argue that her apparent treatment of science as poïesis severely and systematically limited her ability to recognize certain teaching-learning opportunities.

This time the teacher was not effective in blocking students' discourse undesirable for the teacher (if our interpretation is correct, of course). Instead of refining Rachel's mechanism from its anthropomorphism sensed by the teacher, Ebony developed a joke of "tired gravity" (line 209), essentially and effectively torpedoing the teacher's desire, as other peers enthusiastically joined the joke. We wonder if the teacher perceived this joke - their goofing off -- as carnivalesque resistance (cf. Bakhtin, 1984) to her pedagogical regime of scientific mechanisms. It would have been interesting to talk with Ebony and the other children participating in the joke to check if they sensed that the teacher made anthropomorphic mechanisms a taboo in the classroom discussions and they rebelled against this taboo through this joke. 
Of course, Ebony's joke might have been just a joke and not a sign of resistance in their own eyes (or children might have diverse sense of the joke among each other), but we argue what makes Ebony's utterance, "Maybe it's tired. [Laughs]," a joke is its explicit anthropomorphism for gravity contrasted with the official classroom discourse focusing on naturalism for any phenomena they discussed and actively promoted by the teacher. In another classroom context, like for example, writing stories or poetry, tired gravity might not generate any laugh (or it still might but maybe less likely - more research is needed). So, our reply to David Hammer's and Emily van Zee's important questions, "What's the joke? What understanding goes into making it or finding it amusing?" (Hammer \& van Zee, 2006, p. 90) is that we suspect children's carnivalesque resistance to the anthropomorphism taboo as a meaning of their "gravity getting tired" joke.

In our judgment, the teacher's response to the students' joke of "tired gravity" was very deliberate silencing the children by the teacher's switching the legitimate topic of the classroom discussion, "We're going to do something different now with the piece of paper; watch this" (line 223 and then see line 228). Arguably, in four previous times, the teacher's silencing the students' discourses and potential inquiries was not deliberate, but this time it was. In our view, it was not only suppression of the children's carnivalesque resistance to her pedagogical regime but also her admission of helplessness. She did not know what to do. She exhausted herself epistemologically and pedagogically. Her epistemological, pedagogical, and dialogic horizons collapsed. She wanted to move on.

We argue that the teacher's epistemological poïesis, limited as it might be, monologized her pedagogy and the entire classroom discourse. Granted, the teacher's epistemological poïesis of predefined science and mechanisms was much-much more open than the epistemological poïesis of conventional teachers hunting for one or few correct answers by their students. This teacher viewed science and its learning as a process of discourse and authorship. That fact made her pedagogy essentially dialogic. Still, her "seeing science" was predefined on a meta-level of what science is and what kind of mechanisms are legitimate in science. We argue that she still had preset curricular endpoints, although very different from conventional pedagogy. Her preset curricular endpoints were at a meta-level. Arguably, the teacher wanted that at the end of her lessons her students would learn that science is a refinement of their thinking about natural mechanisms about natural phenomena. Elsewhere I (the first author) argued that preset curricular endpoints are birthmarks of the pedagogical excessive monologism (Matusov, 2009, 2018a).

For a teacher, seeing science-as-praxis in a classroom discourse is a peculiar thing. Why is it peculiar? How can a teacher recognize science in a classroom discourse among students, if science is an elusive thing in itself, emerging in and from the practice of the scientists-students?! It reminds us of the paradoxes of the Russian fairytale "Go I Know Not Whither and Fetch I Know Not What"14 or by Socrates in the "Meno" dialogue (Plato \& Bluck, 1961). Paraphrasing Socrates' paradox about research making, one can ask a researcher preparing for a research project, "If you know what you are searching for, why do you search for it?! [Implying that the researcher has already found what she wants to find] But if you don't know for what you are searching, what are you searching for?! [Implying that the researcher is clueless and disoriented]" Both the Russian fairytale and Socrates' research paradox describe praxis. Teacher's seeing science-as-praxis in a classroom discourse with her students is based on all previous definitions of science - by Albert Einstein about a refinement of everyday thinking, by David Hammer and Emily van Zee about mechanisms, by Bruno Latour about elevating modalities of scientists' statements, by Nils Bohn about scientists saying about our experiences and relationships with the world and so on - taking as helpful but always problematic and always limited insights rather than the final definitions. A teacher should expect that her students and she will develop their own helpful, problematic, limited, and elusive - unfinalized -

${ }^{14}$ https://en.wikipedia.org/wiki/Go_I_Know_Not_Whither_and_Fetch_I_Know_Not_What 
definitions of science through their own science practice in the classroom. This teacher orientation can prepare a science teacher to see science in the "to me" discourse, in an anthropomorphic mechanism, in a joke of "tired gravity"15, in a metaphor, in a poetry "The tired wind" by Alvin Willis ${ }^{16}$, and so on.

Yet, we characterize the teacher's pedagogy as deeply dialogic. She accepted and seriously considered any mechanism of the discussed natural phenomena proposed by her students. Her teaching was authorial because she engaged her own mind and heart in trying to understand and engage her students in developing, clarifying, and testing their own mechanism proposals. In this, the teacher treated her students as "a plurality of [opaque, non-transparent] consciousnesses, with equal rights and each with its own world, [that] combine but are not merged in the unity of the event" (Bakhtin, 1999, p. 6, the italics is original). Even when she rejected the students' "tired gravity" as tiresome goofing around, she was willing to revisit the students' contribution and to imagine a serious proposal for a natural mechanism of capricious wind. Arguably, this revisiting is another evidence of the teacher's dialogic pedagogy teacher-orientation. For us, dialogic pedagogy is not "ideal" or "model" teaching but rather a dramatic pedagogy that is full of problematic moments to be considered, analyzed, praised, and, yes, criticized. This makes dialogic pedagogy risky and always contested. In our view, dialogic pedagogy ALWAYS involves missed teachinglearning opportunities and excessive monologism - both required for dialogic critical reflection among professionals (and even students). Our judgment of this teacher's dialogic pedagogy is based on her genuine interest in and commitment to her students' subjectivities and authorship. Her lapses of this commitment and interest and her struggles that we noticed are manifestations of challenges of dialogic pedagogy and not betrayals of it. In our view, it is much healthier to see (and expect) that dialogically minded educators are monologically corrupt than to expect incorruptible "model dialogic teachers" and "model dialogic teaching".

Finally, however limited it might be, in our interpretation and judgment, we argue that the teacherauthor, David Hammer, and Emily van Zee were involved in a dialogic analysis of the case and this and other teachers' dialogic pedagogy in their book. The main goal of dialogic analysis is to deepen meaning of the studied phenomenon, imagine new possibilities, abstract and problematize values, and so on (Matusov et al., 2019, in press). Such a dialogic approach also means to provoke responsive questions by addressing and testing alternative interpretations. This is exactly what the authors and the teachers did in their book. They engaged their mind and heart in recognizing events, interpreting them, meaning making, imagining new possibilities and alternatives and testing them, and making their authorial judgments rather than just focusing on recognizing patterns and their relationships. In our view, these processes constitute dialogic analysis and distinguish it from other traditional types of analysis like, for example, discourse analysis. We will turn to describing and discussing discourse analysis in the following sections.

\section{Postscriptum}

We emailed an earlier draft of our manuscript to David Hammer, Emily van Zee, and the Teacher ${ }^{17}$ for their feedback, hoping to spark their public discussion around our dialogic analysis. To our big surprise, David and Emily became very upset with our critique of the Teacher's teaching practice. The Teacher herself did not respond, although she was probably attending to our intense email communication. At the end of the day, David did not give his permission to publish his objections to our paper. As to Emily, she

\footnotetext{
${ }^{15}$ See a serious online scientific discussion about "tired light=tired gravity" here: https://forum.cosmoquest.org/showthread.php?19195-Tired-Light-Tired-Gravity

${ }^{16} \mathrm{https}: / /$ www.poemhunter.com/poem/the-tired-wind/

${ }_{17}$ We capitalize the Teacher in the Postscriptum to preserve our addressing her directly as an Author, in order to give her back her authorial agency - as a co-author of the dialogic analysis of her case in collaboration with Hammer and van Zee.
} 
requested us 1) to avoid using the Teacher's name in our paper and 2) to add her (Emily's) statement below.

<<Emily van Zee, 2019-01-14: Warning! This paper unethically uses a published video, transcript, and case written by the teacher. Her case provides an outstanding example of a young teacher responding in a respectful way to a student's unexpected comment, opening a conversation in which multiple students participated for an extended time in consideration of the student's claim. This paper's mis-characterization of the dialogue as a case of "silencing" students is misleading and unfair. Emily van Zee, Department of Physics, Oregon State University. Emily.vanZee@science.oregonstate.edu>>

Tina: I want to be considerate and respect the participants' integrity and wishes and therefore protect the teacher's identity, although it was published in the book.

Eugene: I reject Emily's first request because David and Emily published this teacher's teaching practice and reflections using her name. The Teacher's name was revealed and heavily used throughout in the Hammer's and van Zee's book. She clearly became a co-author of the book. I find it very important for our dialogic analysis, to address teachers-practitioners and researchers as authors with equal rights of voice to our own, rather than as mere objects of our analysis. This is especially true when they publicize their practice and research. In our view, any ethical issues of protecting researcher participants' privacy is full responsibility of the original researchers - in this case, David Hammer (the first author of the book), Emily van Zee (the second author of the book), and the Teacher (a signed co-author of the analyzed teaching practice). However, I respect Tina's ethical and personal concerns while disagreeing with them.

Ana: I also respectfully reject Emily's first request for the same reasons as Eugene, but also for one more. In my analysis, watching, and reading the case of "Tired gravity" this, now unnamed, Teacher became to me a big and very real person who I like to address and greatly respect. Not being able to address her by name is like "killing" her as a person for me. But I go along with Tina's wishes and concerns out of respect for Tina, my dear colleague and friend.

Kelly: Although I understand where Emily is coming from, I disagree with her assessment that we are being unethical. I personally feel like we were engaging in dialogic analysis of teaching itself, considering our own assumptions and taken-for-granted practices, which is an important activity in the field of educational research. I do not mean disrespect for this capable teacher and I am sad this is how it was interpreted. However, I do not feel anything is lost by referring to this individual as "teacher."

In our judgment, the tension between David and Emily, on the one side, and us, on another side, goes beyond being personal and represents a paradigmatic difference (including among us). David and Emily think that based on professional ethics, researchers must not make negative judgments about teaching practitioners because it might undermine the practitioners' confidence in themselves and even hurt their public careers. However, in our paradigm, research of teaching practice has to be free from the concerns for the professional development of emerging practitioners as much as possible. Indeed, we think that in the latter, a mentor has to be careful in providing feedback and pay attention to the practitioners' confidence. While saying that, we still disagree that a mentor has to provide only positive feedback and refrain from exploring pedagogical limitations, possible improvements, and even mistakes of the practice with the emerging practitioners (Matusov, 2017). Furthermore, research, especially second-order research as is ours in this paper, has ethical obligations to reveal these pedagogical limitations, improvements, and mistakes in its analysis (dialogic or not). It is up to our readership to judge our paradigmatic and ethical 
dispute. These types of disputes and even emotionally-charged conflicts among researchers seem to be common to dialogic analysis based on dialogic disagreements of authorial judgments.

\section{Discourse analysis of monologic pedagogy: Case\#2 of "true or false" comprehension quizzing}

Famous British scholar of dialogic pedagogy, David Skidmore, developed a discourse analysis of a monologic pedagogy using a case of a language art lesson in a multicultural primary school in south-east England to contrast it with dialogic pedagogy, see Case\#3 (Skidmore, 2000). After reading the story "Rocky's Fox," the teacher quizzed the students about how well they comprehended it by asking them "to consider a series of statements about the story and determine whether they are (1) true (2) false, or (3) there is not enough evidence to decide" (p. 286). Although the text was new, the comprehension quizzing was familiar to the students.

As we join the discussion, they are considering the statement 'He [i.e., Rocky, the main character] heard a dog barking' [which is not true based on the story]; in understanding the sequence it will help the reader to know that, in the story, Rocky hears a barking noise which he knows is not made by a dog; later, a neighbor tells him that it was a fox. One pupil (Kevin) has already argued that the statement is false, but Fiona disagrees, saying: 'It's true 'cause he did hear a dog barking.' The teacher re-reads the relevant section of the story with Fiona, then continues:

1. Teacher: Right. So is it true or false? ([Rocky $\left.{ }^{18}\right]$ ) knew the sound (.) erm(.) 'He heard a dog barking.' Did he hear in the first picture on the first page did he hear that barking (.) to be a dog?

2. Fiona: Yes.

3. Teacher: It wasn't a dog (.) Fiona.

4. Pupils: [Fox. [False $=$

5. Teacher: = It was false because it was a fox barking. How does he know it was a fox barking? 'Cause he described it to Mr Keeping later on and Mr Keeping said ha that's a fox bark. Fox (.) foxes bark like that. Do you understand? Not really do you?

6. Fiona: Erm. (Fiona shakes her head).

7. Teacher: Why do you think that it's a dog barking? You tell me one piece of information from that story to tell you that it's a dog.

8. Fiona: Because erm foxes don't bark and dogs does (.) do.

9. Alex: Foxes [do.

10. Teacher: [OK look at page six Fiona.

11. Alex: Foxes bark like that.

12. Teacher: Page six? OK. Read it with me.

13. Teacher and Fiona: 'The next day Rocky saw Mr. Keeping. He told him about the noise.'

14. Teacher: What noise Fiona? What noise?

15. Fiona: The noise what the fox was making.

16. Teacher: The noise that the fox was making. Which noise was the fox making?

17. Fiona: A dog (.) noise. (Fiona laughs).

18. Teacher: He was barking. The fox was barking yeah? So the noise that he heard in the night. So he told him about the noise. Carry on (.) reading (.) page six. 'That' =

\footnotetext{
${ }^{18}$ In the original text of David Skidmore's article, it is written "Docky", which, we think, was a typo as there is not such character in the book "Rocky's Fox."
} 
19. Teacher and Fiona: = 'will be a fox said Mr Keeping. Foxes bark like that.'

20. Teacher: So.

21. Alex: It's true $=$

22. Teacher: $=$ So the noise he heard on that first page was a bark. He thought it might have been a dog.

23. Fiona: It wasn't.

24. Teacher: But it wasn't a dog. What was it?

25. Fiona: He knew it wasn't a dog.

26. Teacher: What was it?

27. Fiona: It was a fox.

28. Teacher: It was a fox. And the statement says on your sheet 'He heard a dog barking.' Did he hear a dog barking?

\section{Kevin: No.}

30. Teacher: So is it true or false?

31. Fiona: [False.

32. Richard: [It was false.

33. Teacher: Do you understand?

34. Fiona: ${ }^{\circ}$ Yes. $^{\circ}$

35. Teacher: OK next sentence (pp. 286-288).

In his discourse analysis of the case, Skidmore abstracted and focused on structural and functional patterns of the discourse. As we argued above, this focus constitutes a discourse analysis. Thus, for example, Skidmore noticed a structural pattern of the teacher-student talk ratio being near $50 \%$, noticing that "nearly half of her turns are convergent or 'test' questions, i.e. questions which have a pre-specified answer already known to the teacher $(1,14,16,24,26,28,30)$, and which typically elicit from the pupil a yes/no answer, or the recitation of a word or phrase from the text" (p. 288), which is in itself a functional discursive pattern. Skidmore commented that this structural-functional pattern "of the dialogue thus approximates to a sequence of IRE exchanges" - teacher's Initiation, student's Response, and teacher's Evaluation, noticed by many previous researchers and critics of monologic conventional pedagogy (e.g., Lemke, 1990; Mehan, 1979; Sinclair \& Coulthard, 1975). Skidmore also connected this IRE triadic discourse of monologic pedagogy with scaffolding "the student's learning by reducing the degrees of freedom for the learner and accentuating critical features of the task (Mercer, 1992, 1994; Wood, Bruner, \& Ross, 1976; Wood \& Wood, 1996)" (p. 288) - another structural-functional discursive pattern.

In contrast to Case\#1, in Case\#2, neither the teacher nor the researcher was much engaged with their mind and heart into deepening meaning making of the students' and the teacher's contributions. For the teacher, the lesson was mainly making all students arrive at preset curricular endpoints (e.g., although fox barks like a dog, it is not a dog). For the researcher, his discourse analysis of the lesson was mainly to reveal the structural-functional patterns of a generic monologic pedagogical discourse. Thus, one can legitimately argue that discourse analysis of monologic pedagogy is congruent with monologic pedagogy itself and, hence, is appropriate and justified. We agree with that, but to a point. As interchangeable teachers can similarly quiz comprehension of different texts (or other curriculum) by these or different students in the same way; interchangeable scholars can similarly apply a similar discourse analysis to any monologic pedagogy, revealing its diverse structural-functional patterns.

Yet, both the data and David Skidmore's discourse analysis are pregnant with a dialogic analysis in our view. The story in the focus of this class' discussion, "Rocky's Fox" by Tessa Krailing (1989) is filled with complex dilemmas for, emotions of, relationships among its characters, and plot twists, using dramatic, 
sympathetic and even somewhat humorous narrative and illustrations in our reading. It is about a young boy, Rocky, who hears strange noises at night, somewhat similar to dog barking, but he knows it is not a dog. Helped by a good neighbor, Mr. Keeping, Rocky discovers that a fox moved into a hole under a shed in his garden. He learns that the fox had stolen some food from the dustbins of a nearby fish and chips store. The store owner prepares a trap to catch the perpetrator. But as the story progresses, we learn that Rocky is concerned for the fox and the next night he saves it from getting trapped. His neighbor, Mr. Keeping shares this concern and helps Rocky feed the fox in his garden to avoid being trapped by the fish and chips store owner. Rocky, then, also discovers that the fox is a mother with several babies. Instead of the fox, Rocky's dog, Max, gets trapped, but the store owner gives him back to Rocky, advising him to take better care of him. The danger is now over, the store owner satisfied with "catching the perpetrator," while the fox family lives safely in Rocky's garden.

It could have been interesting to ask the teacher what might attract her attention in the fragment if anything, whether she was satisfied with her guidance or not and why. Specifically, we would like to ask the teacher if she thought that:

1) Fiona knew that foxes don't actually bark like dogs and in her answer (turn 8) challenged the author and the characters in the story who imply that foxes may "bark" exactly like dogs;

2) Fiona could not understand why people (the author of the story, the teacher, and some of her peers) called the sounds that foxes make "barking;"

3) after the classroom exchange, Fiona sincerely realized that the poetic simile between the foxes' noises and dog barking was legitimate;

4) after the classroom exchange, Fiona strategically pretended to agree that foxes "bark" to stop forceful imposition of disagreeable ideas on her by the teacher and by some of her classmates, while secretly believing on the contrary;

5) something else might have happened (what?).

Do these options matter for the teacher and why or why not? What was the basis for Fiona to reject characterization of foxes' sounds as barking? Was the teacher under strong pressure of all her students passing high stake tests by any means possible or not? What does it mean for the teacher that her students deeply understood the studied material in general and in this particular moment with Fiona about barking foxes? Was it important for her? If so, why? If not, why not?

Furthermore, how do the teacher and other kids know that foxes bark? Do all foxes bark or only some? Under what circumstances barking foxes bark? What would convince Fiona that foxes can bark like dogs? What would convince the teacher and the other kids that they are wrong? Are barking foxes indistinguishable from barking dogs? Is "fox barking" a figurative saying in comparison with dog barking i.e., foxes produce a noise very remotely sounding like dog barking, - as Fiona seemed to suggest? Or is "fox barking" a literal expression - i.e., foxes bark exactly or nearly exactly like dogs and can be confused with dogs in this regard, - as the teacher and some other students argued? Our own mini-investigation on the Internet, which was, probably, unavailable back then in the 1990s when the lesson was held, supports Fiona's and not the teacher's stand,

All species of fox have a pretty wide variety of vocalizations, just as dogs and cats do. It's simple to reduce, say, a dog's vocalizations to "bark," but as any owner knows, dogs can yelp, whine, howl, 
growl, and make all kinds of other sounds. Foxes aren't quite as varied in their vocalizations as dogs, but they're still capable of making lots of different sounds.

The most commonly heard red fox vocalizations are a quick series of barks, and a screamy variation on a howl. All fox vocalizations are higher-pitched than dog vocalizations, partly because foxes are much smaller. The barks are a sort of ow-wow-wow-wow, but very high-pitched, almost yippy. It's commonly mistaken for an owl hooting. That bark sequence is thought to be an identification system; studies indicate that foxes can tell each other apart by this call ${ }^{19}$ (Nosowitz, 2013, September 5, italics are ours).

Finally, for us and for now, why are foxes and dogs so similar in their vocal behavior? Are they biologically related or there is some other reason for this similarity? Of course, we would like to know what else attracted the kids in this interesting book and why, if anything?

At the end of this discourse analysis of conventional monologic pedagogy, David Skidmore apparently tried to dialogize his primarily discourse analysis by imagining alternative moves by the teacher,

\begin{abstract}
Allowing for the constraints imposed by the support materials in this case, we might nevertheless ask whether alternative responses by the teacher at specific points could have lent a more productive turn to the dialogue. Would Fiona's learning have been better assisted, for example, if at turn 3 the teacher had requested her to elaborate on the reasoning behind her (mistaken) thinking, instead of making a straightforward contradiction? What if Fiona's statement 'foxes don't bark' (turn 8) had been treated as an opportunity to open the floor to other pupils, rather than directing the group's attention immediately back to the text? These instances can be seen as critical turning-points in the discourse, where the teacher's utterances influence the shape and tone of the subsequent interaction, in this case pushing it in the familiar direction of teacher-dominated recitation, but where alternative choices were available which might have challenged the pupils to engage in a higher level of literate thinking (p. 289).
\end{abstract}

However, in our judgment, Skidmore's alternative suggestions remain structural-functional in their nature. He did not focus on what might have been the connections - for the students and the teacher, - between this particular episode in the story when Rocky hears barking noises that he knows are not made by a dog, and the rest of the dramatic events in the story. We do not see how he engages his mind and heart in the issues at hand that the participants faced. His imagination remains organizational in its nature -- "What if Fiona's statement 'foxes don't bark' (turn 8) had been treated as an opportunity to open the floor to other pupils, rather than directing the group's attention immediately back to the text?" His justification, and thus pedagogical values, remain structural-functional, in our view, "a higher level of literate thinking," rather than unique, personal, contextual, and authorial.

Similarly, when David Skidmore directly addresses the teacher through his research assistant, in our judgment, he does not try to engage himself into genuine dialogic contact with the teacher. He wrote,

Responding to my analysis of this extract, the student who recorded the episode argued that my criticism of the teacher's decision to require Fiona to reread portions of the story (turns 13 and 19) was misconceived, since it failed to take sufficient account of the teacher's instructional goals. A primary purpose of this activity, she argued, was to encourage the pupils to develop the skill of retrieving specific information from the text. From this point of view, the strategy of returning to the text and testing the student's literal understanding of the narrative material was precisely what was

\footnotetext{
${ }^{19}$ You can hear a fox's "barking" in the cited article and here: https://www.youtube.com/watch?v=ulR8RtI9kaw
} 
needed. Against this, I would want to ask how confident we can be that Fiona's independent competence in close reading has indeed been strengthened as a result of this interchange; and whether the model of comprehension enacted here is appropriate to the genre of text under consideration (pp.289-290).

We agree with David raising an important issue about the nature of Fiona's acceptance of the teacher's "fact" that foxes can bark like dogs. However, without talking or addressing the teacher, it is unclear (at least for us) what her pedagogical goal was. We can think of several possibilities. First, the teacher might have wanted to engage Fiona in the production of facts - unfolding internally persuasive discourse leading to a consensus that foxes can bark, - something that David Skidmore apparently is interested in. Alternatively, the teacher might not be interested in teaching her students about production of facts, but rather consumption of facts -- what constitutes the quality of epistemological authority to believe. Yet, another possibility is that the teacher might have planned to teach something completely different - even a deep dialogic exploration of the story, but the barking foxes were in her way of doing that, so she decided to deal quickly with barking issue in an authoritarian way, like, "Trust me, foxes bark," and move on something more important (e.g., discussing perspective taking by the book characters). All three (or more?) alternatives for the teacher's possible goals -1 ) the production of facts, 2) the consumption of facts, and 3 ) the prioritization of the dialogic pedagogy - could have been explored by the researcher. Finally, for us and for now, David Skidmore's position is a bit unclear for us: why the teacher's focus on teaching Fiona to closely analyze the text was less promoting her independence than David's suggestion to discuss the text with her peers. And why is students' "independent competence" an important a pedagogical value for him in the first place?

\section{Discourse analysis of dialogic pedagogy: Case\#3 of who is most guilty in "Blue Riding Hood"}

In the same article (2000), Skidmore describes and analyzes another pedagogical event which he characterizes as an instance of dialogic pedagogy. In this case, a group of 5-6th grade students in a multicultural urban primary school in south-east England are discussing "their views on the characters in a story called Blue Riding Hood (Hunt, 1995)" (p. 290). As Skidmore explains in his article, the "Blue Riding Hood" is a parody of the familiar fairy tale "Red Riding Hood", where all the characters are subverted and recreated as not always behaving well. The teacher asked the pupils "to discuss the story and try to put the characters in order, from least to most blameworthy" (p. 290). As we join the discussion, the group has just been judging which character was most guilty of "bad behavior," talking about the character of the wolf in the story; the teacher now moves them on to consider others.

1. Teacher: Okay we have other characters. Who should we discuss next?

2. Ian: Erm (.) the woodcutter.

3. Teacher: Where does he come on the scale [of the guilt]?

4. lan: Near the end.

5. Suma: Because when she [i.e., Blue Riding Hood] was wandering around in the forest and he [i.e., the woodcutter] met her and the he told her that he's going to show her grandmother how to behave (.) and he had an axe and (.) the the (.) he took the skin off the wolf and he killed grandma.

6. Ian: No they [i.e., the Woodcutter and the Blue Riding Hood] didn't know there was bears in the forest and erm there they thought she would just get lost in the woods.

7. Kulvinder: But the woodcutter bashed granny's door down. 
8. Penda: I don't think he was well behaved (.) because he should have come and talked to her not smash her house down.

9. Suma: Yeah but granny still behaved in the same way even when the woodcutter was in her house.

10. Kulvinder: Granny (.)was mean and she was just horrible she just tells her [Blue Riding Hood] to get out of the house. [...] (There is a hiatus in the transcript at this point because the audiotape had to be changed while the group continued to talk.)

11. Teacher: Okay should we now try to put the characters in some sort of order?

The teacher seems to stop the discussion with this question dictated by the instructional manual for how to teach this story! (see the preparation pages in the "Blue Riding Hood" story instructional material, Hunt, 1995, pp. 30-31).

12. Kulvinder: Woodcutter (.) granny Blue Red Riding Hood and the wolf.

13. Colin: I had the wolf then the woodcutter then Blue Riding Hood then granny.

14. Ian: I had Blue Riding Hood the wolf the woodcutter then granny.

15. Suma: The woodcutter the Red Riding Hood the wolf then granny granny.

16. Penda: The wolf the woodcutter Blue Riding Hood then granny.

17. Teacher: It is very difficult isn't it? I would say the wolf although we agreed his behaviour was far from perfect. Then I would say (.) you need to think about what happened. Granny threw Blue Riding Hood out of the house yeah? Erm now that was quite deliberate $=$

18. Ian: = A witch.

19. Penda: Yeah she started everything it was all her fault (.) if she hadn't thrown Red I mean Blue Riding Hood none of this would have happened.

20. Kulvinder: But Blue Red Riding Hood killed the wolf.

21. Penda: ${ }^{\circ}$ Oh yeah. ${ }^{\circ}$

22. Colin: None of them were really nice.

23. Ian: No.

24. Penda: But whose fault was it?

25. Suma: I think granny's.

26. Colin: But she didn't kill any one.

27. Penda: No but it was her fault really wasn't it?

28. Kulvinder: She wasn't very nice (.) well I didn't like (.) she deserved to be eaten.

29. Colin: She wasn't killed on purpose was she?

30. Ian: The woodcutter killed her.

31. Colin: No she was eaten by bears.

32. Ian: I mean it was his fault he erm chucked her out.

33. Teacher: Well we have run out of time. I think you have done very well. I thought it was hard to sort them out but you together all of you have done that really well. I don't think there is a right or wrong answer if there was we wouldn't have had much to talk about." (Skidmore, 2000, pp. 290-291).

David Skidmore starts his analysis as a dialogic analysis engaging into the very dialogues in the excerpt, seemingly with the purpose to evaluate "how dialogic" was the pedagogy in this episode. He problematizes some of the teacher's pedagogical organizational/structural decisions to not elaborate on some points that the students' offered, and wonders if some deepening of the dialogues would be more beneficial to the students. 
It could be argued that the pupils in this sequence would have benefited from being asked to elaborate or unpack some of their more elliptical comments (e.g. turn 5). It also seems a pity that the teacher feels obliged to terminate the discussion before the pupils have had chance to compare their views on all the characters systematically; as it stands, the discussion has only touched on their views about one of the central characters in the story (Blue Riding Hood) (p. 291).

$\mathrm{He}$ is mostly interested in finding structural and functional characteristics of the episode. He shows marked contrast to the Episode \#1 (our Case\#2, see above) that can be used to characterize this discourse as "dialogic" through structural and functional aspects of the classroom discourse. For example, he attracts the reader's attention to distributions of turns among all speakers, where the teacher's participation is proportionally far less prominent than in the Episode\#1 (i.e., structural aspect of discourse). The dynamics of turns between the speakers is far from the monologic teacher - less the IRE pattern (structural). The teacher asks authentic information seeking questions, genuinely inviting students to explain their views, rather than information-known questions as in the Episode\#1 (Case\#2) (functional). The teacher acts as a facilitator of the students' engaged discourse, rather than a conduit of preset knowledge (functional). Students address each other more than they address the teacher, "it is normal for pupils to address questions to each other" (p. 292) (structural). Furthermore, Skidmore picks up some other structural and functional characteristics of this discourse: the use of the "modal propositions", "hypothetical statements ("he should have come..."), alternative counter-fictional propositions,

Pupils explain the reasons for their views about the story, collectively exploring its polysemic potential; in so doing they are necessarily involved in glossing the text, re-interpreting the significance of events in the narrative in an act of retelling which goes beyond the words on the page; cf. the use of amodal proposition by one pupil in turn 8 ('he should have come and talked to her'), or the hypothetical statement in turn 19 ('if she hadn't thrown ... Blue Riding Hood none of this would have happened') (p. 292).

David Skidmore also describes the dynamic of students addressing and challenging each other, considering each other's points of view, etc. and finally judges that the classroom discourse represents "internally persuasive discourse" - the term coined by Bakhtin (1991). This is also a functional coding of the discourse by David Skidmore, in our judgment. The following-up contrasting comparison of the Cases \#2 and \#3 by David Skidmore is almost completely based on his structural-functional discourse analysis.

Ironically, in contrast to the Case\#2, described above, we could not find any meaning making dialogue by David ${ }^{20}$ about the ideas expressed in the lesson or the unfolding events, neither with the students nor with the teacher. It is ironic because Case\#2 was a case of monologic pedagogy, according to David Skidmore (and we agree), while Case\#3 was a case of limited dialogic pedagogy, according to him and we again concur with his authorial judgment. In our view, David's analysis was more dialogic of monologic pedagogy and purely discursive, i.e., positivist, analysis of dialogic pedagogy.

We see several tensions among children in assigning a degree of guilt based on negative consequences of the story characters' actions (e.g., Suma, turn 5; Kulvinder, 7; Suma, 9; Kulvinder, 10) versus on the characters' intentions and knowledge (e.g., lan, 6; Penda, 8),

\footnotetext{
${ }^{20}$ We asked David Skidmore to comment on our analysis but unfortunately, he could not do that due to personal reasons not related to our paper.
} 
5. Suma: Because when she [i.e., Blue Riding Hood] was wandering around in the forest and he [i.e., the woodcutter] met her and the he told her that he's going to show her grandmother how to behave (.) and he had an axe and (.) the the (.) he took the skin off the wolf and he killed grandma.

6. lan: No they didn't know there was bears in the forest and erm there they thought she would just get lost in the woods.

In turn 19, Penda seemed to introduce yet another basis of assignment of guilt by considering who started the mess, "Yeah she [granny] started everything it was all her fault (.) if she hadn't thrown Red I mean Blue Riding Hood none of this would have happened."

It seems to us that although the involved children sensed the disagreement among each other, neither they nor the teacher apparently recognized and defined the tension, if our interpretation is correct ${ }^{21}$. We definitely would ask the children and the teacher a question about this tension and how they defined the guilt and assigned it to the characters.

In the turn 11, the teacher asked the students (again?) to rank the characters by their guilt of bad behavior. In turns 12-16, some children provided diverse answers. We wonder why the teacher did not ask the children to provide the reasons behind of their ranking.

Ana: However, to give both the teacher and the students credit, after reading the two-page story "Blue Riding Hood" (Hunt, 1995, pp. 133-134), I conclude that the story itself is a rather bad, even senseless quasi parody of the classic fairytale "Little Red Riding Hood" - where the task of the story is to make everyone "bad" - but without any motivation why would such change be meaningful. I feel very sad and disappointed with the story in the first place: there is no moral dilemma - the message is just that everyone is bad. The question about "degrees" of moral corruption seems a false question for me. I don't see it as actually educational - since it does not lead to any insights that can be revealing about ethics, in my view. It is probably not easy for the teacher and for the students to engage in genuine dialogue about it, I mean the degree of guilt, except probably developing a genuine critique of it, which would go against the didactic material, the teacher used. But even with this story a dialogue could be developed about the children's questions about what is good/bad. And they have just started - when the $30 \mathrm{~min}$ was over and the teacher cut them off. "sigh!

Eugene: Dear Ana, I respectfully disagree with you. I found the "Blue Riding Hood" story interesting, full with working-class (and peasant) humor and sensibilities similar to the classical medieval French fairytales (Darnton, 1984). Let me retell the gist of the story (i.e., its plot). The Blue Riding Hood heads to her old grandmother, who lives in woods, to give the grandmother cakes in exchange of getting a dinner. However, the girl gets lost in the woods. The Wolf volunteers to help the girl and brings her to the grandmother's house. For his work, the Wolf demands the girls' cakes. When the girl hesitates, the Wolf threatens the girl with a bite. The clever girls offer a cake covered with a poison. The Wolf eats the poisoned cake and dies. The girl comes to the grandmother who gets

${ }^{21}$ Tina: See a similar phrase below: I don't think we, ourselves, should join the traditional monologic paradigm by suggesting "accurate" or "correct" interpretations. But I understand the intention behind this phrase, I think. However, I suggest that we delete it and instead proudly show that we don't care about the correctness of our interpretations at all? We rather represent creative, situated and embodied voices in its relativity?

Eugene: An interesting issue. In my view, we should be concerned about correctness of our interpretation because otherwise we would talk on behalf of people, which is rather monologic to me. The teacher and even kids might recognize the disagreements but might strategically ignore them for a while for whatever reason. I think we should be humble in our interpretations when we do not have access to the participants to ask them directly (we could still disagree with them but at least we would have asked them). What do you think? 
upset that the girl did not bring all cakes for her and also that the girl is late. The grandmother expels the girl to the woods late at night. The girl is frightened but meets the Woodcutter. The Woodcutter and the girl violently force themselves to the grandmother's house and send her to the woods where she gets eaten by a bear. The Woodcutter marries the Blue Riding Hood and they live happily ever after.

In my view, the story is full of motivations - sometimes rather selfish and violent but also mundane and at times even noble and generous - of common people of low means, struggling in making their ends meet. It could have been fun to consider and judge these motivations: possible rights and wrongs of them. For example, the Wolf was apparently nice, volunteering to help the Blue Riding Hood girl, although he did not tell her in advance that he wanted to be paid by her with her cakes. The Wolf has a family that he supports, making him apparently a good parent, -- a half of the cakes would go to his family. Knowing that in advance, the girl might reject his help. But the Wolf threatened the girl with biting, - thus, setting her mind on a counter-offense of poisoning and killing him. Each of the characters' motivation and action were understandable and even somewhat justified, but also highly questionable. The carnivalesque humor of plain folks involves constant flipflop of power, described by Bakhtin in his analysis of novels by French medieval writer Rabelais (Bakhtin, 1984). The powerful and scary Wolf was trumped by the Blue Riding Hood, who tricked and poisoned him to death; the Blue Riding Hood was bullied by her Grandmother, who sent her Granddaughter to the forest at dark night; finally, the Grandmother was violently de-crowned (Bakhtin's term) by the Woodcutter and the Blue Riding Hood, who made the Grandmother taste her own medicine by sending her to dark night forest. At the same time, I agree with Ana that the characters felt empty, lacking, in my view, a sense of humanity in their relationship with each other. In my judgment, the story is pregnant with dialogic inquiries both for the students and for the teacher that unfortunately did not realize in the lesson.

In our brief dialogic analysis, we also took into account the didactic materials the teacher apparently used to organize this teaching unit (Hunt, 1995, pp. 30-31). In those materials we read: "Discuss, with the whole class, the orders of blame arrived at by different groups. Encourage the children to justify their choices by referring to specific parts of the text" (p.30). Thus, we see the teacher's question to the children in turn 11, "Okay should we now try to put the characters in some sort of order?" not as a dialogic question - a serious question based on the teacher's real interest in what the students think - but as the teacher following a preset didactic strategy aimed to arrive at certain preset curricular endpoints ("To prompt the children to discuss the behaviour of the characters in a story; justifying their judgements of who is most and least blameworthy by referring back to the text" (p. 30)).

Eugene: Dear Ana, as you wrote the text of the paragraph above, I wonder what exactly made the teacher monologic, in your view. Was it her use of the pre-existing didactic materials? My answer is "yes" and "no." I can envision a teacher using pre-existing didactic materials to promote a genuine dialogue with her/his students. In this case, the pre-existing didactics serves as a dialogic provocation for the students and the teacher who become genuinely interested with their minds and hearts in addressing each other and the provocation - wherever it may lead them. Unfortunately, this did not happen in the Case\#3. Rather, and I agree with your judgment, it seems that the teacher mechanically followed the didactics, without dialogically engaging in it and with her students. The students tried to address the teacher's disinterested question without much addressing and questioning the story or even each other.

Ana: I agree that a preset monologic teaching instruction can be used as a provocation. But in this case, the teacher does not use the material as a provocation, not does she enter into a dialogue together 
with the students. In my view, she seems to use these instructions to get back "on track" with the class as prescribed, without guiding students into a deeper analysis of their positions and ideas.

Accordingly, in her turn 17, the teacher asked the children to focus closely on what happened in the story. This pedagogical move reminds us of the teacher from Case\#2. It is interesting that David Skidmore does not seem to notice this parallel that the teachers in both cases tried to focus the students on the text and not on considering the differences among each other. We also wonder, based on our reading of the didactic materials used by the teacher in Case\#3, if she might have tried to guide her students to the preset curricular endpoints, albeit in much looser, "constructivist," consensus-seeking way than the more traditional teacher of Case\#2. Maybe, pedagogy in Case\#3 is much less dialogic than David Skidmore and we (initially) thought. The teacher's relativistic statement ending the discussion (turn 33), which we found rather decontextualized and not very thoughtful, but David apparently likes "no uniquely "correct"' answers, supports our suspicion that this class was not much dialogic. In our view, when faced with the diversity of ideas and opinions, a dialogic approach would focus on putting these diverse ideas in critical contact with each other, comparing them and contrasting, them, creating assumptions implied by each diverse idea and checking them, etc. Instead, the teacher conclusion about the relativity of "the right and the wrong answers," remains monologic. If we are accurate in our interpretation, we would like to ask both the teacher and David Skidmore why they are ideologically attracted to this universal relativism.

Speaking in general, we wonder if a researcher's focus on Discourse Analysis, on identifying structural and functional patterns, makes it difficult for the researcher to recognize a dialogic pedagogy because the latter requires the researcher to focus on deepening the participants' authorial meanings and to engage in dialogue with them. This may suggest that a discourse analysis, focusing on revealing functional-structural patterns, is not sufficient to recognize, analyze, and critically meaningfy dialogic pedagogy. Research on dialogic pedagogy may require a dialogic analysis.

Finally, at the end of our essay, we want to make a "big picture" comment. In our view, at the beginning of the $21^{\text {st }}$ century, people around the world have experienced two types of oppressions: 1) oppression by positivism/modernism that tries to manage people like objects signified by "big data", "best practices", "research-driven, evidence-based policies," "universal truth," "consensus among rational and informed people," and so on; and 2) oppression by "post-truth," "alternative facts," "identity politics," "relativism," and "post-fact" of social engineering. We see a trap in fully rejecting or fully accepting either positivism or social engineering as such. In our view, dialogic research preserves positivism of factdiscovery while curbing it through authorial meaning-making of these facts. At the same time, dialogic analysis recognizes the legitimacy of authorial actions transcending reality, which social engineering can be a part of, and demands responsibility for it from its actors in a critical dialogue.

Now, we are turning to comparing and contrasting dialogic analysis and discourse analysis through a dialogue among us.

\section{Conclusion}

\section{Question\#1: Is discourse analysis always positivist and monologic?}

Tina: I think we should be careful with equating all types of discourse analysis with positivism. Is it more convincingly with the distinction monologic vs. dialogic science? For example, I am thinking of Linell (2009) who distinguishes between monologistic vs. dialogistic science. Accordingly, he views monologism as a counter-theory to dialogism. As far as language and language use are concerned there are essentially two authorities to lean on in this contrasting paradigm of science: "the individual speakers and the language system, the latter of course being ultimately (at least partly) 
based on implicit social contracts among users. These are the sovereign 'monological' meaningdeterminers." (p. 35). With such a distinction, the monologic paradigm is understood as containing positivism or, as Bakhtin terms it, "exact science" (Bakhtin, 1986) among other more or less monologistic approaches to science, language and dialogue. What do you think?

Ana: I think that discourse analysis in its ideological approach is always positivist - because it tries to capture the "objective," the "given," "how things really are," the phenomenon as it is in its essence, independent of anyone's subjectivity. For David Skidmore - it is not important what the students or teachers think as people, why they think so, what might it mean to them, etc., e.g., all what is a dialogic revelation of their voice in an encounter with the text and with each other. What is important for him are forms and processes of ANY dialogue as a process in which human subjectivities figure as ephemeral, local input into much more universal systematic process, conceptualized as something that (positively) exists, i.e. as a positive given that any independent, disinterested researcher (i.e. without subjectivity) could discover, observe, describe, analyze and interpret coming to the consensus with others that they are observing the same given phenomenon. In that sense, discourse analysis strives for a consensus about the assumed given reality - i.e., it is positivist.

In fact, the Case\#3 actually beautifully shows that looking for the formal characteristics of the dialogic pattern can lead one to conclude that there is dialogue where it actually does not exist for the actual pedagogy. In the Case\#3, we can actually see how a discourse analysis can completely miss finding a dialogue, when it only looks at the superficial structural and functional patterns. Thus, in this case we can discern what seems to be just the beginning of a serious dialogue, but only for the children, and NOT for the teacher, who seems to have followed the preset instructions of the didactic material, rather than to have engaged and tried to lead an authentic dialogue! The teacher's remarks in lines \#11 and \#33 interrupt and stop the actual dialogues that the children are trying to have amongst themselves. What do you think?

Tina: I fully agree to your interpretation of the episodes; how the teacher deliberately chose to kill the dialogicity in her preplanned effort to pursue her teaching that relied on instructional material about how to teach this story. She therefore seemed to forget to be attuned to the emerging ontological dialogue that took place between the children (as in our Case\#1 where some peers continued to engage vividly in a conversation of the mystery of gravity when the teacher decided to suddenly move on). Line \#11 in Case\#3 is a bit complex to analyze though, due to the fact that we do not know how the peer discussion (and the discussion between the students and the teacher) really unfolded. There is a long transcriptional break because the researcher had to fix a new audiotape to the following recording. So, I am not sure whether the teacher interrupted the discussion abruptly or not. [Ana: Good point!!] We know nothing about the adjacent preceding conversational episode, unfortunately. However, as far as I can see, I do think that also Skidmore noticed this and was quite concerned about it throughout his analysis of precisely this case. What do you think was missing? What do you mean should be added in order to be an even more dialogical analysis?

Ana, let me now turn to your proposed take on positivism, as you identify some fundamental features here above. They are thought-provoking, but I think we must discuss how positivism could be, or should be, defined in relation to existing interpretations of the term. In my eyes there are a number of definitions throughout history when coming to the scientific paradigm of positivism. On the one hand, some scholars should agree that just seeking after visible empirical realities in terms of what is "positively given" is a kind of general positivism (cf. Hall, 1987; Ritzer \& Stepnisky, 2018, p. 108). But on the other hand, it is commonly argued that positivism in the strictest sense methodologically, has more to do with the dominant norm of studying social phenomena with the 
same methods as the natural sciences. One crucial implication following from such a paradigmatic guideline is the focus of discovering stable, invariable and universal laws and outcomes which are both possible to generalize and predict in subsequent studies.

However, poststructuralist (and postmodern) discourse analyses, for example critical discourse analysis and discourse psychology analysis (e.g., Potter's version, see Potter, 1996). Are you sure that also these analytic approaches assume a (pre)given essence, seeking mere objectivity? I thought they were highly relativistic perspectives and, thus, anti-essential in their postmodern outlook, although I can understand what you are problematizing when stating that they have an ambition to be "objective", i.e. independent of human subjectivity, and so forth. The latter is interestingly also discussed in Sullivan's (2011) book on dialogic analyses, in the light of a variety of discourse analyses. He seems to support the idea that dialogical research does not neglect human subjectivities, neither the participants' nor the researcher's (although he seems not to contrast it with positivism what I can see so far). For instance, he says,

In other varieties of discourse analysis, the temptation is to uncover the power dynamics, including unconscious, social and historical power dynamics, which are responsible for the organization of truth-claims in discourses (e.g., Fairclough, 1992; Parker, 1992; Walkerdine, 1987). Much of this suspicion of the truth-claims of the talk derives from French philosophy, including Jacque Lacan, Ferdinand de Saussure, Roland Barthes and Michel Foucault (see Kress, 2001). They argue that the author is one who reproduces and adds to social meanings but whose intentions are largely irrelevant to the organization and study of the talk. In both these varieties of discourse analysis, the text is an object of suspicion and the author is ambivalently spoken of as either a strategic agent or ultimately irrelevant to the production of the text (Sullivan, 2011, p. 10).

Furthermore, I agree that it is important to notice how discourse analysis may be based on arriving at consensual facts or truths. I prefer to conceptualize this monological dimension as a finalizing research approach that stands in sharp contrast to a non-finalizing methodology where the authors, as we try to do here, never claim we had arrived at final truths. I therefore see our suggested conclusions as tentative, highly temporary instances of finalizations, left open for validation by the research communities and all the readers and participants involved, including us. We are not stable and may find it reasonable to deconstruct our insights later on, in response to critique or questions addressed to us.

Eugene: I think ALL pure discourse analysis, as such, is monologic and positivist, unless it is deeply embedded in a dialogic analysis. I think discourse analysis as such is positivist because it mainly focuses on how things really are - i.e., on the given, rather what the things subjectively and authorially mean for different people, including the researchers, in an unfolding dialogic contact. Of course, discourse analysis cannot escape meaning/sense making but often it is often very uncomfortable with deepening meaning/sense as it is afraid to lose its objectivity, generalizability, and validity.

I think that there is a confusion of sociocultural and cultural-historical contextual positivism that fights universal and decontextualized positivism with dialogism. Sociocultural and cultural-historical contextual positivism (e.g., Vygotsky and neo-Vygotskians) studies how culture, history, institutions, economy, and so on (i.e., diverse forms of the contextually given) shape, mediate, and, thus, pattern human behavior, activity, and discourse. In contrast, dialogism studies how people transcend, author, address, and reply to their diverse given contexts - i.e., the culturally, socially, 
biologically, historically, politically, and economically given. I want to contrast contextual positivism and dialogism with the following quotes about child development:

\section{Contextual sociocultural positivism}

The following quote from Per Linell's book nicely illustrates the contextual sociocultural positivism that I am talking about,

According to a Vygotskyan sociocultural theory, the individual also partially repeats the sociohistorical evolution. What the child today learns in culture and in school in, say, mathematics, took humanity centuries and millennia to develop. Nowadays, individuals and groups are crucially dependent on the support of cultural (cognitive) artifacts, such as pen-and-paper, the abacus, the slide rule, the mini-calculator or personal computer, but with the help of these, they learn to master complex mathematical operations and can move into domains of much more advanced knowledge than was ever possible for earlier generations who belonged to other sociocultures (Linell, 2009, p. 253).

\section{Dialogism}

In contrast, dialogism can be illustrated by Alexander Lobok's critique of traditional psychology,

For an 'objective' external onlooker, the childhood of different children is largely indistinguishable. All children play certain games, absorbedly listen to fairytales, react to various events, and so on. In fact, nearly all modern psychology research testifies to these 'childhood uniformities' and their typologies. The reason for this supposed uniformity is a flaw in the main approach of modern psychology. Modern psychology often focuses on universal, generalizable, predictable, and regular principles, which is the standard of the science. Anything else is viewed as nonscientific. How else it can be?!

The problem with this conventional approach to psychology, however, is that the human being is the only 'object' in the Universe that is defined by a subjective cognizing world of her or his own, building above the subjective lived experiences and feelings and redefining them - a world, unique for each person, which cannot possibly be viewed from outside, except for some of its outward objective artifact manifestations of this subjective cognizing world. If so, a question emerges: can a particular human being, his/her particular and unique subjective cognizing world be a subject of science - a subject of scientific observation and interpretation? Can a particular child with his/her unique subjective world, subjective Cosmos, not overlapping with subjective cognizing worlds of all other people in principle, be a subject of science?

Thus, for a researcher, it would appear strange to avoid addressing this individually subjective world since it is exactly the disparities of people's inner subjective experiences that, in all likelihood, make up our essence as humans. It is not what a person has in common with other people what makes her or him become a unique personality. On the contrary, what makes one a genuine person is precisely what he or she by no means shares with the others. I strongly argue that the phenomenon of childhood is not defined by those things that make children of a certain age group category look mostly alike. Childhood, rather, is made of 
diversity of children's views, experiences, and fantasies that are unique for each person and different from anyone else's experiences. Probably, this nonoverlapping of human subjectivities is the deepest and the most important enigma of human beings (Lobok, 2017, p. Sla2).

While sociocultural positivism looks for predictable contextual patterns organized in systems, dialogism looks for unique meaning to author it and, then, to address it.

Tina: I agree that your Vygotsky-illustration above seems to be driven by a seemingly confusing principle of law: the idea that an individual also partially repeats the sociohistorical evolution. Without denying it, I would like to say some words about how a contemporary sociocultural approach generally approaches learning issues, with our positivism-discussion in mind.

A basic idea following from a sociocultural perspective on learning is the assumption that the world is construed differently in different discourses and social practices. Learning is then ultimately about discovering how different discourses and premises for participation are made relevant, or productive, in certain activities (Säljö, 2011). Säljö problematizes the traditional (positivistic) dualism that divides mental and abstract (e.g. psychological) knowledge on the one hand, and practical, concrete (e.g. physical) knowledge on the other. One implication for the positivistic notion is related to language and its social functions. Here language is said to strictly represent the social realities, if applied properly. If we happen to "misrepresent" the reality in our inappropriate choice of words, it is consequently judged as an individual mistake. However, it does not really matter because the world is ultimately not contingent on how we chose to conceptualize aspects of it. From a sociocultural stance, knowledge formation rather starts with dialogues: "The origin of knowledge is simply in social interaction and not in internal psychological processes" (Säljö, 2011, p. 68, Tina's translation from Swedish).

In his critique to classical individualistic takes on learning and language, Säljö accordingly turns to the epistemological relativity in the human processes of learning and linguistic meaning making through various situations and contexts in life. There are no predictable, universal laws for analysts to rely on, and no uniform methods for uncovering regularities of such phenomena. He clearly illustrates how sociocultural interpretations differ from positivistic approaches, in this sense. In the end it is all about subjective (and intersubjective) interpretations, situated in a complex layer of norms for what counts as scientifically valid knowledge.

As discussed throughout our text, however, positivism is not an unambiguous term. I doubt that what you call "sociocultural positivism" is looking for predictable patterns in the classical positivist way, but I agree about your concern that identifying contextual (and interactional) patterns tends to be a central concern in many sociocultural studies, perhaps at the price of participants', or researchers' own, subjectivities. In contrast, 'dialogic dialogism' addresses and discusses unique meanings between authors/speakers, without reducing individual meaning making.

Kelly: Tina, Ana and Eugene - This is a very compelling discussion and there are good points on both sides. When I first read the question, my reaction was, discourse is not purely positivist. My rationale was similar to Tina's point that "one crucial implication following from such a paradigmatic guideline is the focus of discovering stable, invariable and universal laws and outcomes which are both possible to generalize and predict in subsequent studies." Coming from a constructivist perspective, the function and structure of language is one that is co-constructed by the users of the language over time. In Gee's book on Discourse Analysis (2011), he says that language follows "two closely related functions: to support the performance of social activities and social identities and to support human affiliation within cultures, social groups, and institutions" (p. 1). In this way, I 
think discourse analysis has a hard time reaching positivism because the laws of language are not universal and always predictable. However, I can see Eugene's point about how discourse analysis "mainly focuses on how things really are - i.e., on the given, rather what the things subjectively and authorially mean for different people, including the researchers, in an unfolding dialogic contact." I think if we were to restrict discourse analysis to the most momentary structure and rules of language that are mutually agreed upon, then I would say that it is positivist. I would agree that dialogic analysis is further away from positivism than discourse analysis, so maybe it's an issue of shades of gray rather than black or white, being that it is or is not entirely positivist.

\section{Question\#2: How do Discourse Analysis and Dialogic Analysis complement each other?}

Eugene: Without a little dialogism, positivism is meaningless, treating people as predictable and calculatable zombies run by their universal biology or by their contextual socioculturalism. Without little positivism, dialogism is groundless, mystifying the human authorship (Matusov \& MarjanovicShane, 2017; Matusov et al., 2019, in press). Discourse Analysis and Dialogic Analysis need each other: Dialogic Analysis makes Discourse Analysis meaningful, while Discourse Analysis makes Dialogic Analysis grounded. Positivism and dialogism need each other. For example, in Case\#1, the students, the teachers, the researchers, and we, the authors of this paper, tried to make sense of the patterns of the students' experiences, patterns of their and our ideas, patterns of their and our discourses by addressing and replying to each other. All of us were engaged in positivism: objectivizing and finalizing our authorship and contributions. At the same time, all of us engaged in dialogism: making sense of each other's ideas and contributions, challenging each other, taking seriously each other, addressing each other, replying to each other, testing each other's diverse and often conflicting ideas, and inviting our readers to join our dialogue. Neither pure discourse analysis nor pure dialogic analysis is, strictly speaking, possible. Discourse analysis has to be liberated from its ideological fear of contamination with dialogic authorial meaning making.

On the other hand, positivism and dialogism are incompatible, for many reasons. Probably, one of most important reasons is that positivism is aiming at reaching for a consensus among relevant people as a proxy for the truth (Latour, 1987), while dialogism is unfinalizable, in principle (Nikulin, 2010). Positivism values the relationships of agreement and consensus, while dialogism prioritizes disagreement, dissensus, and mis- and non-understanding (Matusov, 2015). Another important reason is that positivism tries to eliminate researchers' subjectivity and authorship, while dialogism strives for subjectivity and authorship. When positivism studies subjectivity, it reduces it to "objective subjectivity" - making it stable, predictable, calculable, and measurable. Dialogism studies authorial subjectivity, which is unique, unpredictable, relational, and immeasurable (Matusov, 2019, submitted; Matusov et al., 2019, in press).

Ana: I agree with Eugene and want to add a few more thoughts about the differences between dialogism and positivism. I see positivism as in principle aiming at construction of commonly (if not universally) accepted truths as a platform for collaborative action. With its "high modality" of expression that erases subjectivities in the construction of the academic "facts" (Latour, 1987) positivism is calling for the suspension of disbelief (Marjanovic-Shane, 2016), asking the students to trust and to follow the authority. Positivism is meant to dissuade and even block doubt, and by that, to block further critical inquiry, especially in education. In other words, it strives to promote the belief in the established truths and, thus, to influence researchers (and students) to act in a certain way, or risk losing "social goodies." Gee's perceptive quotation about a "good student" can be adapted for a "good scientist." 
In this sense, even though practices like being a "good [scientist]" are not really games-their "rules" or conventions are usually much less formal-there are, in these practices, in a sense, "winners" and "losers." The winners are people who want to be accepted as a "good [scientists]" and gain such acceptance. The "losers" are people who want such acceptance, but do not get it (Gee, 2011, p. 6).

In that sense, positivism leads to socialization as the principle of research, i.e., to moving individuals from a non-member or a peripheral member of a particular group to a full-fledged member of that group that can be recognized as following the social "rules" of that community.

On the other hand, dialogism, with its disagreements, dissensus, and mis- and non-understanding, is about "lowering modality," (Latour, 1987), doubting the "facts", inquiring about their origins, construction, and truth. Dialogism is about suspending belief (Marjanovic-Shane, 2016), doubt and deconstruction. It aims at re-establishing subjectivities, desires, contexts and relationships and critically evaluating all the "earlier stages in the construction of facts" (Latour, 1987, p. 25). In that sense, dialogism is not promoting collaborative action, nor socialization into the community of (academic) practice. Rather, it is promoting critical testing ideas and developing richness of diverse points of view, as well as continuing search for evidence, all of them necessary for creating internally persuasive discourse (Bakhtin, 1991; Matusov \& von Duyke, 2010).

I also agree that positivism and dialogism need each other. Dialogue in principle does not have a beginning nor an end, and researchers may want to come to some point when they stop any further deconstruction - either because they exhausted arguments or evidence or because a further deconstruction may seem to be irrelevant) and agree that they reached a truth they claim to be "the truth." In a sense, a dialogic research may end up with establishing "new facts" and a temporary abandonment of further doubt - reaching a point of agreement about "the given".

As for the positivism, it needs to be prepared to open up the "black boxes" of truth (Latour, 1987) at any time, welcoming new problematizations and dialogizations. Otherwise, it may stop being a scientific practice, and become a dogma, impervious to new points of view, new evidence and new social and cultural paradigms.

\section{References}

Akutagawa, R., \& Lippit, S. M. (1999). The essential Akutagawa: Rashomon, Hell screen, Cogwheels, A fool's life and other short fiction. New York: Marsilio.

Alexander, R. J. (2004). Towards dialogic teaching: Rethinking classroom talk: Dialogos Cambridge.

Aristotle. (2000). Nicomachean ethics (R. Crisp, Trans.). Cambridge, UK: Cambridge University Press.

Bakhtin, M. M. (1984). Rabelais and his world (H. Iswolsky, Trans. 1st Midland book ed.). Bloomington: Indiana University Press.

Bakhtin, M. M. (1986). Speech genres and other late essays. Austin, TX: University of Texas Press.

Bakhtin, M. M. (1991). The dialogic imagination: Four essays by M. M. Bakhtin (C. Emerson \& M. Holquist, Trans.). Austin, TX: University of Texas Press.

Bakhtin, M. M. (1999). Problems of Dostoevsky's poetics. Minneapolis: University of Minnesota Press.

Creswell, J. W. (2007). Qualitative inquiry \& research design: Choosing among five approaches (2nd ed.). Thousand Oaks, CA: Sage Publications.

Darnton, R. (1984). The great cat massacre and other episodes in French cultural history. New York: Basic Books.

Denzin, N. K. (1978). The research act: A theoretical introduction to sociological methods (2d ed.). New York: McGrawHill. 
Denzin, N. K., \& Lincoln, Y. S. (2005). The SAGE handbook of qualitative research (3rd ed.). Thousand Oaks, CA: Sage Publications.

Einstein, A. (1936). Physics and reality. Journal of the Franklin Institute, 221(3), 349-382.

Fairclough, N. (1992). Discourse and social change. Cambridge, UK ; Cambridge, MA: Polity Press.

Gee, J. P. (2011). An introduction to discourse analysis: Theory and method (3rd ed.). New York: Routledge.

Hall, R. T. (1987). Emile Durkheim: Ethics and the sociology of morals. New York: Greenwood Press.

Hammer, D., \& van Zee, E. (2006). Seeing the science in children's thinking: Case studies of student inquiry in physical science. Portsmouth, NH: Heinemann.

Hunt, G. (1995). Reading: Key stage two, Scottish levels C-E. Leamington Spa: Scholastic.

llyenkov, E. V. (2009). The ideal in human activity. Pacifica, CA: Marxists Internet Archive.

Krailing, T. (1989). Rocky's Fox. London, UK: MacMillan Education, LTD.

Kress, G. (2001). From Saussure to critical linguistics: The turn towards a social view of language. In M. Wetherell, S. Taylor, \& S. Yates (Eds.), Discourse Theory and Practice: A Reader

(pp. 29-47). Milton Keynes: Open University Press.

Kumar, M. (2008). Quantum: Einstein, Bohr and the great debate about the nature of reality. Thriplow, UK: Icon.

Latour, B. (1987). Science in action: How to follow scientists and engineers through society. Cambridge, MA: Harvard University Press.

Latour, B. (1993). We have never been modern. New York: Harvester Wheatsheaf.

Latour, B. (1996). Aramis, or, The love of technology. Cambridge, MA: Harvard University Press.

Latour, B. (1999). Pandora's hope: Essays on the reality of science studies. Cambridge, Mass.: Harvard University Press.

Latour, B., \& Woolgar, S. (1979). Laboratory life: The social construction of scientific facts. Beverly Hills, CA: Sage Publications.

Lemke, J. L. (1990). Talking science: Language, learning, and values. Norwood, NJ: Ablex Pub. Corp.

Linell, P. (1998). Approaching dialogue: talk, interaction and contexts in dialogical perspectives. Amsterdam ; Philadelphia, PA: J. Benjamins Pub. Co.

Linell, P. (2009). Rethinking language, mind, and world dialogically: Interactional and contextual theories of human sense-making. Charlotte, NC: Information Age Pub.

Lobok, A. M. (2017). The cartography of inner childhood: Fragments from the book. Dialogic Pedagogy: An International Online Journal, 5, Sla1-Sla42.

Marjanovic-Shane, A., Meacham, S., Choi, H. J., Lopez, S., \& Matusov, E. (2019). Idea-dying in critical ontological democratic dialogue in classrooms. Learning, Culture and Social Interaction, 20, 68-79. doi:10.1016/j.lcsi.2017.10.001

Matusov, E. (2009). Journey into dialogic pedagogy. Hauppauge, NY: Nova Science Publishers.

Matusov, E. (2011). Authorial teaching and learning. In E. J. White \& M. Peters (Eds.), Bakhtinian pedagogy: Opportunities and challenges for research, policy and practice in education across the globe (pp. 21-46). New York: Peter Lang Publishers.

Matusov, E. (2015). Comprehension: A dialogic authorial approach. Culture \& Psychology, 21(3), 392-416. doi:10.1177/1354067X15601197

Matusov, E. (2017). How to engage practitioners from across the learning landscape in the research enterprise: Proposal for phronêtic research on education. Integrative Psychological and Behavioral Science, 51(1), 94119. doi:10.1007/s12124-016-9365-3

Matusov, E. (2018a). Mapping dialogic pedagogy: Instrumental and non-instrumental education. In A. Rosa \& J. Valsiner (Eds.), The Cambridge Handbook of Sociocultural Psychology (2nd ed., pp. 274-301). Cambridge, UK: Cambridge University Press

Matusov, E. (2018b). What kills science in school?: Lessons from pre-service teachers' responses to urban children's science inquiries. Integrative Psychological and Behavioral Science, 52(2), 257-287. doi:10.1007/s12124-0189415-0

Matusov, E. (2019, submitted). Dialogic analysis of a lesson on the educational controversies of religious holidays in a dialogic multi-regime college classroom. International Journal of Qualitative Studies in Education. 
Matusov, E., \& Marjanovic-Shane, A. (2017). Bakhtin's mystical organic holism and its consequences for education. Dialogic Pedagogy: An International Online Journal, 5, DB61-DB74. doi:10.5195/dpj.2017.222

Matusov, E., \& Marjanovic-Shane, A. (2019). Intrinsic education and its discontents. In L. Tateo (Ed.), Educational dilemmas: A cultural psychological perspective (pp. 21-40). New York: Routledge.

Matusov, E., Marjanovic-Shane, A., \& Gradovski, M. (2019, in press). Dialogic Pedagogy and Polyphonic Research: Bakhtin by and for Educators: Palgrave Macmillan.

Matusov, E., \& von Duyke, K. (2010). Bakhtin's notion of the Internally Persuasive Discourse in education: Internal to what? (A case of discussion of issues of foul language in teacher education). In K. Junefelt \& P. Nordin (Eds.), Proceedings from the Second International Interdisciplinary Conference on perspectives and limits of dialogism in Mikhail Bakhtin Stockholm University, Sweden June 3-5, 2009 (pp. 174-199). Stockholm: Stockholm University.

Mehan, H. (1979). Learning lessons: Social organization in the classroom. Cambridge, MA: Harvard University Press.

Mercer, N. (1992). Culture, context and the construction of knowledge in the classroom. In P. Light \& G. Butterworth (Eds.), Context and cognition: Ways of learning and knowing (pp. 28-46). Hemel Hemstead: HarvesterWheatsheaf.

Mercer, N. (1994). Neo-Vygotskian theory and classroom education. In B. Stierer \& J. Maybin (Eds.), Language, literacy, and learning in educational practice: $A$ reader (pp. 92-110). Clevedon: Multilingual matters/Open University.

Nikulin, D. V. (2010). Dialectic and dialogue. Stanford, CA: Stanford University Press.

Nosowitz, D. (2013, September 5). What sound does a fox really make? Popular Science. https://www.popsci.com/science/article/2013-09/what-sound-does-fox-make

Nystrand, M. (1997). Opening dialogue: Understanding the dynamics of language and learning in the English classroom. New York: Teachers College Press.

Parker, I. (1992). Discourse dynamics: critical analysis for social and individual psychology. London ; New York: Routledge.

Plato, \& Bluck, R. S. (1961). Meno. Cambridge, UK: University Press.

Potter, J. (1996). Representing reality: Discourse, rhetoric and social construction. London: Sage.

Ritzer, G., \& Stepnisky, J. (2018). Sociological theory. Los Angeles: SAGE.

Säljö, R. (2011). Kontext och mänskliga samspel: Ett sociokulturellt perspektiv på lärande. [Context and human interaction: A sociocultural perspective on learning]. Utbildning \& Demokrati, 20(3), 67-82.

Sinclair, J. M., \& Coulthard, M. (1975). Towards an analysis of discourse: The English used by teachers and pupils. London: Oxford University Press.

Skidmore, D. (2000). From pedagogical dialogue to dialogical pedagogy. Language and Education, 14(4), 283-296.

Skidmore, D. (2016). Pedagogy and dialogue. In D. Skidmore \& K. Murakami (Eds.), Dialogic pedagogy: The importance of dialogue in teaching and learning (pp. 98-110). Bristol, UK: Multilingual Matters.

Sullivan, P. (2011). Qualitative data analysis using a dialogical approach: SAGE.

Tobin, J. J., Davidson, D. H., \& Wu, D. Y. H. (1989). Preschool in three cultures: Japan, China, and the United States. New Haven: Yale University Press.

Tobin, J. J., Hsueh, Y., \& Karasawa, M. (2009). Preschool in three cultures revisited: China, Japan, and the United States. Chicago: The University of Chicago Press.

Trappes-Lomax, H. (2004). Discourse analysis. In A. Davies \& C. Elder (Eds.), The handbook of applied linguistics (pp. 133-164). Malden, MA: Blackwell Pub.

Walkerdine, V. (1987). No laughing matter: Girls' comics and the preparation for adolescent femininity. In J. M. Broughton (Ed.), Critical Theories of Psychological Development. New York: Plenum Press.

Wells, C. G. (1999). Dialogic inquiry: Towards a sociocultural practice and theory of education. New York: Cambridge University Press.

Wood, D., Bruner, J. S., \& Ross, G. (1976). The role of tutoring in problem solving. Journal of Child Psychology and Psychiatry, 17, 89-100.

Wood, D., \& Wood, H. (1996). Vygotsky, tutoring and learning. Oxford Review of Education, 22(1), 5-16. 
Dialogic analysis vs. discourse analysis of dialogic pedagogy Eugene Matusov, Ana Marjanovic-Shane, Tina Kullenberg, Kelly Curtis

\section{(cc) $\mathbf{E Y}$}

New articles in this journal are licensed under a Creative Commons Attribution 4.0 United States License.

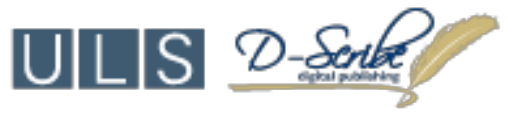

This journal is published by the University Library System, University of Pittsburgh as part of its D-Scribe Digital Publishing Program and is cosponsored by the University of Pittsburgh Press. 